\title{
Cerebral Laterality, Emotion, and Cardiopulmonary Functions: An Investigation of Left and Right CVA Patients
}

\author{
Clinton S. Comer \\ Dissertation submitted to the faculty of the Virginia Polytechnic Institute and State University in \\ partial fulfillment of the requirements for the degree of \\ Doctor of Philosophy \\ In \\ Psychology
}

David W. Harrison, Chair

Russell T. Jones

D. Michael Denbow

George A. Clum

April 23, 2014

Blacksburg, Virginia 


\title{
Cerebral Laterality, Emotion, and Cardiopulmonary Functions: An Investigation of Left and Right CVA Patients
}

\author{
Clinton S. Comer
}

\begin{abstract}
Stroke, or cerebrovascular accident (CVA), is a prominent cause of long term disability in the United States. It has been evidenced that the outcome of a CVA patient differs as a function of the cerebral hemisphere that is damaged by the stroke, especially in terms of emotional changes. The Right Hemisphere Model of Emotion posits that the right hemisphere is specialized for processing emotional content, regardless of valence. In contrast, the $\mathrm{Bi}$ Hemispheric Model of Emotion posits that each hemisphere has its own emotional specialization. The current experiment tested the competing predictions of the two theoretical perspectives in a mixed sample of left cerebrovascular accident (LCVA) patients and right cerebrovascular accident (RCVA) patients using a Dichotic Listening task and the Affective Auditory Verbal Learning Test (AAVLT). Heart Rate (HR) and Pulse Oxygen Saturation (SpO2) were also recorded as sympathetic measures. It was expected that the predictions of the BiHemispheric Model would be supported. A series of mixed design ANOVAs were used to analyze the data. Results revealed that both groups may have exhibited decreased auditory detection abilities in the ear contralateral to CVA location. Additionally, CVA patients recalled significantly more positive words, than negative or neutral words, and exhibited a significant learning curve. LCVA patients exhibited a recency effect, while RCVA patients exhibited a heightened primacy effect. Findings from HR and SPO2 measures suggested a parasympathetic response to neutral information as well as an impaired sympathetic response to negative information in RCVA patients. Taken together these results lend partial support to the hypotheses drawn from the Bi-Hemispheric Model of Emotion, as evidenced by the diametrically opposite effects in these groups, which appears to reflect opposing cerebral processes.
\end{abstract}




\section{Table of Contents}

Chapter 1 - Introduction ........................................................................................... 1

1.1 - Right Hemisphere Model of Emotion .......................................................... 1

1.2 - Bi-Hemispheric Model of Emotion .................................................................... 4

1.3 - Current Experiment ................................................................................... 7

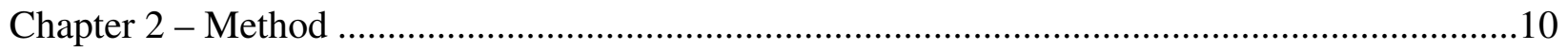

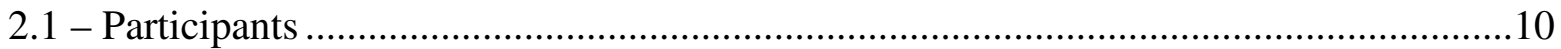

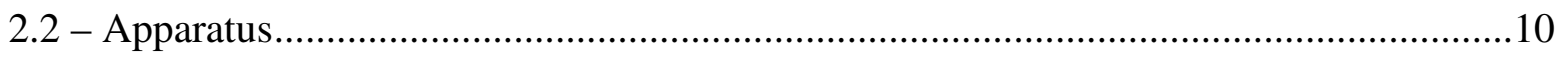

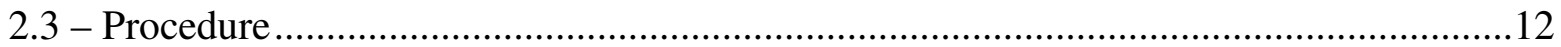

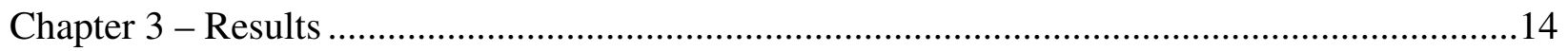

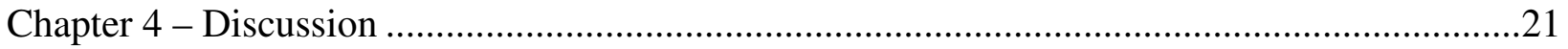

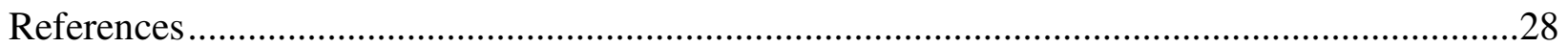




\section{List of Figures}

Figure 1 - Mean number of words recalled at each trial for each list by left and right

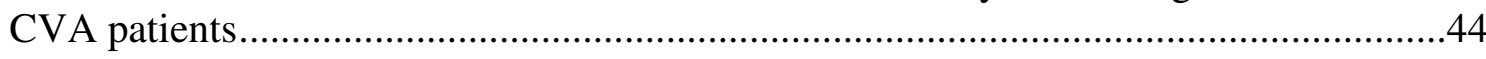

Figure 2 - Mean heart rate at each condition for each list by left and right CVA patients ................45

Figure 3 - Mean pulse oxygen saturation levels at each condition for each list by left and

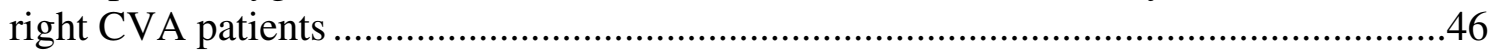




\section{List of Tables}

Table 1 - Frequency table for CVA location, gender, age, and years of education .......................40

Table 2 - Mean scores for MAS, AAVLT, and Dichotic Listening performance

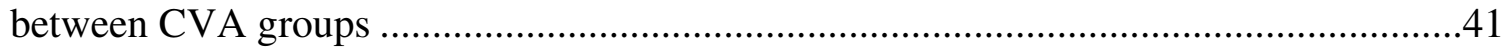

Table 3 - Mean scores for HR and SPO2 measures between CVA groups .................................42

Table 4 - Mean number of words recalled on each trial of the AAVLT between CVA groups 


\section{Appendices}

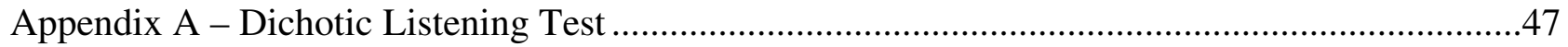

Appendix B - Affective Auditory Verbal Learning Test ....................................................48

Appendix C - Coren-Porac-Duncan Laterality Test..............................................................49

Appendix D - Mood Assessment Scale ................................................................................50

Appendix E - Linear Progression of Positive List before Negative List Procedure ........................52

Appendix F - Linear Progression of Negative List before Positive List Procedure........................53 


\section{Chapter 1 - Introduction}

The most recent update from the American Heart Association estimates that approximately 795,000 people suffer a stroke each year (Roger, et al., 2011). This means that every 40 seconds, someone in the United States has a stroke. Stroke, also known as cerebrovascular accident (CVA), is a leading cause of long term disability (Centers for Disease Control and Prevention, 2001). Despite these prominent statistics, stroke victims and their family members are often left with little knowledge of the behavioral changes that may remain long after the recovery process reaches a plateau.

Neuropsychological research provides a useful framework to study stroke and its effects. Specifically, neuropsychologists are able to use instruments that measure behavioral changes over time across a wide variety of domains, such as cognitive, emotional, perceptual, and expressive abilities. Neuropsychologists also frequently incorporate physiological measures of the central and autonomic nervous systems, which are commonly impacted by strokes. Taken together, these assessment capabilities make it possible to identify and diagnose strokes, assist in treatment planning and caregiver education, as well as make prognostic predictions regarding patient rehabilitation. For example, largely through neuropsychological and neurological investigations, it has been evidenced that the outcome of a CVA patient differs as a function of the cerebral hemisphere that is damaged by the stroke (e.g. Goldstein, 1939; Heilman, Scholes, $\&$ Watson, 1975; and others). These observed differences are the essence of Functional Cerebral Laterality Theory. Patients with left frontal dysfunction are often diagnosed with depression, where amotivation, apathy, self-depreciating concerns, and low energy level are observed (e.g. Banich, Stolar, Heller, \& Goldman, 1992; Debener et al., 2000; Fleminger, 1991; Henriques \& Davidson, 1991). However, a CVA in the right hemisphere often results in indifference and a caustic attribution towards other people (see Demaree, Everhart, Youngstrom, \& Harrison, 2005; \& Shenal, Harrison, \& Demaree, 2003, for reviews). This work is relevant to neuropsychology because there are contrasting theoretical perspectives regarding the role of each hemisphere and emotion.

\section{1 - Right Hemisphere Model of Emotion}

One theoretical perspective regarding the role of lateralized hemispheric function and emotion perspective is the Right Hemisphere Model, which posits that the right hemisphere plays 
a greater role in processing emotions regardless of valence (Heilman, 1982). Such emotional dominance logically follows from the right hemisphere dominance for regulating bilateral cortical arousal levels (Howes \& Boller, 1975; Green \& Hamilton, 1976; Heilman, Schwartz, \& Watson, 1978; Heilman \& Van Den Abel, 1979; Heller, 1993), as any intense emotion requires arousal or activation. Sympathetic reactions to emotional events are also associated with right hemisphere activation (Wittling, 1990; 1997), which is said to be the primary anatomical location for emotional comprehension and emotional expression (Heilman, 1997). The lateralization of emotion preferentially to the right cerebral hemisphere has been presented numerous times within the literature by Heilman (Heilman, Blonder, Bowers, \& Valenstein, 2003; Heilman \& Bowers, 1990; Heilman, Bowers, \& Valenstein, 1985; Heilman \& Gilmore, 1998) as well as others (Borod, Koff, \& Caron, 1983; Borod, 1992; Bryden \& Ley, 1983; Buck, 1984; Ross, 1985, Tucker, 1981).

The notion of right hemispheric specialization for emotion can be traced back to Mills (1912a, 1912b), who noted that patients with right hemisphere lesions displayed decreased emotional expression, and Babinski (1914), who reported that such patients were often indifferent to their disabilities. Also, patients with right temporoparietal lesions exhibited deficits in comprehending the emotional affect of speech (Heilman, Scholes, Watson, 1975). While much of the early work leading up to the Right Hemisphere Model focused primarily on the posterior regions of the brain, especially the parietal lobes (Denny-Brown, Meyer, \& Horenstein, 1952), researchers subsequently expanded its application into the frontal lobes (Heilman, Blonder, Bowers, \& Valenstein, 1993). This work lends itself to suggest that the right hemisphere maintains an excitatory role over the reticular activating system, and the left hemisphere possibly portrays an inhibitory role over the right hemisphere or the reticular activating system (Heilman, 1997). Support for this notion has been found in patients with right-frontal lobe damage who have decreased regulatory control over emotions, (Heilman, Bowers, \& Valenstein, 1993; Robinson, Parikh, Lipsey, \& Starkstein, 1993; see Shenal, Harrison, \& Demaree, 2003; \& Carmona, Holland, \& Harrison, 2009, for a comprehensive review). Such right frontal lobe dysfunction is also associated with hyperarousal, as there is diminished regulatory control over the reticular formation via the descending projections as well as less regulatory control over the right poster brain regions via the longitudinal tract (Shenal, Harrison, \& Demarre, 2003; Carmona, Holland, \& Harrison, 2009; Foster, Drago, Ferguson, \& Harrison, 2008). 
Support for the Right Hemisphere Model has grown to include right hemisphere dominance during emotional provocation (Borod, Vingiano, \& Cytryn, 1988; Tucker, Roth, Arneson, \& Buckingham, 1977) and in the comprehension and expression of emotional prosodic speech (Borod, Andelman, Obler, Tweedy, \& Welkowitz, 1992; Borod et al., 1998, 2000, Borod, Bloom, Brickman, Nakhutina, \& Curko, 2002; Bowers, Coslett, Bauer, Speedie, \& Heilman, 1987; Emerson, Harrison, \& Everhart, 1999; Heilman, Scholes, and Watson, 1975; Schmitt, Hartje, \& Willmes, 1997). Additionally, there is evidence for right hemisphere specialization in the perception of negative emotional faces (Herridge, Harrison, Mollet, \& Shenal, 2004; Mandel, Tandon, \& Asthana, 1991; Wittling \& Roschmann, 1993) and in the expression of emotional facial gestures (Borod, Haywood, \& Koff, 1997; Herridge, Harrison, \& Demaree, 1997; Rhodes, $\mathrm{Hu}, \&$ Harrison, 2000).

Support also comes from findings that the left hemisphere attends to primarily right-sided stimuli, whereas the right hemisphere attends to stimuli within either hemispace (Heilman \& Van Den Abell, 1980). In the vast literature on neglect disorders, research findings are consistent that left hemispatial neglect is far more common than right hemispatial neglect, due to the attentional specialization of the right hemisphere (Heilman, Watson, \& Valenstein, 2003). Similarly, Borod (1992) suggests that these nonverbal, spatial, and integrative abilities of the right hemisphere give this hemisphere an advantage for processing emotions.

While studies of individuals with brain damage provides an understanding of the functional systems underlying emotion (Borod, 1993), research in non-brain damaged populations also yields information supporting the Right Hemisphere Model. Consistent with studies of hemispatial neglect, high-hostile participants identified facial affect faster when faces were presented to the left visual field (right hemisphere) than to the right visual field (Harrison \& Gorelczenko, 1990). Likewise, in the auditory modality, a left ear advantage (right hemisphere) has been found for emotion identification (Bryden \& MacRae, 1989).

Electrophysiological and neuroimaging studies provide useful information regarding the right hemisphere specialization for emotion processing. Herridge, Harrison, \& Demaree (1997) asked high-hostile participants to make angry facial expressions and found that the galvanic skin response (GSR) of these individuals was heightened and prolonged at the left hemibody (right hemisphere). Studies utilizing electroencephalography (EEG) have yielded greater relative right hemisphere activity during the processing of facial affect (Kestenbaum \& Nelson, 1992; Munte 
et al., 1998; Vanderploeg, Brown, \& Marsh, 1987) and the processing of the emotional components of speech (Bostanov \& Kotchoubey, 2004; Everhart, Carpenter, Carmona, Ethridge, $\&$ Demaree, 2003). More recent functional magnetic resonance imaging (fMRI) studies have found similar evidence for the right hemisphere's involvement in the perception of facial emotion (Narumoto, Okada, Sadato, Fukui, and Yonekura 2001; Sato, Kochiyama, Yoshikawa, Naito, \& Matsumura, 2004) and affective prosody (Buchanan et al., 2000; George et al., 1996; Imaizumi et al., 1997).

In a review of the literature, Silberman and Weingartner (1986) concluded that the largest amount of consistency supported the right hemisphere being dominant for emotion. There is abundant evidence supporting the notion that the perceptual and expressive processes regarding emotion, as well as the autonomic arousal processes, are asymmetrically represented in the cerebral hemispheres. Recent literature reviews of depression and other related studies continue to lend support to the model (Carmona, Holland, \& Harrison, 2009; Demaree, Everhart, Youngstrom, \& Harrison, 2005; Holland \& Harrison, in press; Mollet \& Harrison, 2006, Kopp \& Wessel, 2008; Shenal, Harrison, \& Demaree 2003).

\section{2 - Bi-Hemispheric Model of Emotion}

In contrast to the Right Hemisphere Model, a Bi-Hemispheric Model of Emotion such as the Valence Model posits that the right hemisphere is specialized for negative emotion and that the left hemisphere is specialized for positive emotion (Ehrlichman, 1987; Silberman \& Weingartner, 1986; Borod 1992; Buck, 1984; Heilman \& Bowers, 1990; Ross, 1985). This model postulates that the right hemisphere is dominant in processing and expressing negative emotions and that the left hemisphere is dominant in processing and expressing positive emotions.

Differential hemispheric specialization for emotion dates back to Goldstein (1939), who reported "catastrophic reaction" in patients with left hemisphere lesions whereas patients with right hemisphere lesions were indifferent or euphoric. Others had recognized that each hemisphere is capable of independent mental processes (Sperry, 1966), and different styles of processing (Levy, 1969), where the left hemisphere processes analytically and the right hemisphere processes holistically. Prior to the Valence Model, researchers investigating hemispheric specialization viewed the left hemisphere as inhibitory to the emotional and arousal processes of the right hemisphere (Tucker, 1981). For example, Shearer and Tucker (1981) 
presented aversive and sexual stimuli, and found that participants used verbal and analytic thinking to inhibit arousal, whereas participants used global ideation to facilitate emotion. A similar study by Tucker and Newman (1981) presented aversive and sexual slides while implementing self report measures and skin temperature recordings. Results showed that verbal and analytic cognition could be used to inhibit emotional arousal.

Tucker was aware that emotion involved an activation or arousal component, and that the basic systems that modulate cortical arousal appeared to be lateralized. Therefore, more evidence supporting the left hemisphere's involvement related to cognition and positive emotion was needed. Tucker viewed the differing cognitive skills of the two hemispheres as a basis for emotions being lateralized. However, early efforts to find positive emotion in anxiety populations were unsuccessful, as mood level appeared to be mostly related to the arousal level of the right hemisphere (Tucker, 1981).

Before the Valence Model, evidence for right hemisphere involvement in negative emotion was plentiful. However evidence for left hemisphere involvement in positive emotion was more difficult to derive. For example, Dimond, Farrington, and Johnson (1976) presented motion pictures to either the left or right hemisphere through the use of special contact lenses which restricted vision to the half field. Films presented to the left half field (right hemisphere) were rated more negatively, which suggested that the right hemisphere is biased towards a negative evaluation of incoming stimuli. Ultimately, differential activation research was needed to begin supporting positive versus negative hemispheric contributions. Davidson, Schwartz, Saron, Bennett, and Goleman (1979) asked participants to continuously indicate their emotional responses to television programs. Left frontal activation was observed during positive affect and right frontal activity was observed during negative affect. Similarly, results were replicated when participants were asked to generate thoughts and feelings associated with positive or negative experiences. Consistency regarding these differential hemispheric specializations began to accumulate through studies of frontal activation (Ahern \& Schwartz, 1985; Jacobs \& Snyder, 1996; Tomarken, Davidson, Wheeler, \& Doss, 1992).

Following the establishment of the Valence Model, theoretical bases followed from the findings of many researchers. These researchers sought possible explanations as to why the left and right hemispheres would be specialized for different emotions. One such explanation posited that negative emotions are linked with survival (Borod, Koff, \& Buck, 1986), whereas positive 
emotions are more linguistic and communicative (Borod, Caron, Koff, 1981). The notion of the left hemisphere pertaining to verbal communication and pleasantness carried the Valence Model into research on approach/withdrawal behaviors (Davidson, 1984; Davidson, Ekman, Saron, Senulis, \& Friesen, 1990; Fox, 1991). However, the original predictions of the Valence Model were not lost. Tucker and Frederick expanded the Valence Model into the Balance Model of Emotion (Tucker \& Frederick, 1989).

While Heilman et al. (1993) had primarily looked at the effects of cerebral lesions, Tucker and Frederick (1989) discussed the effects of relative cerebral activation on emotions. The Balance Model provided a basis for deactivation of a particular hemisphere secondary to inhibitory influences of the homologous frontal lobe. Decreased activation of one hemisphere is posited to result in relative activation of the opposite hemisphere. Therefore, relative deactivation of the right cerebrum is said to result in increased relative activation of the left cerebrum which results in an increase of positive emotion. Similarly, relative deactivation of the left cerebrum is said to result in an increase of negative emotion. With this extension to the Valence Model, the Balance Model provides a framework for including deactivation of a functional cerebral system as an inherent part of emotion, thereby suggesting the need for a balance in these processes. Specifically, according the model, activation and deactivation occurs as a result of the system attempting to balance itself (Tucker, 1981; see Mollet \& Harrison, 2006; Shenal, Harrison, \& Demaree 2003 for reviews). This balance is a function of the dynamic activation on tasks where the brain is differentially specialized, as evidence by metabolic increments on fMRI, and where capacity limitations are shown in unilateral lesion studies.

Evidence for the dynamics between hemispheres can be traced back to early research on the emotional reaction that typically follows unilateral brain damage, as dynamics are represented through the ongoing communication and inhibitory processes of the two hemispheres. One such line of research comes from performing the WADA test on epilepsy patients. Sodium amytal was often injected into the carotid artery as an ipsilateral transient hemispheric anesthetic. Anesthesia of the right hemisphere has been characterized by a euphoric reaction, whereas anesthesia of the left hemisphere results in dysphoria (Lee, Loring, Meader, \& Brooks, 1990). The emotional changes that were observed in patients following the WADA test have been interpreted to be the result of the release of one hemisphere from the inhibitory control of the other hemisphere. Similar conclusions have been drawn from studies of patients with 
unilateral brain damage. It has been argued that damage in one hemisphere releases the activity of the other hemisphere (Robinson Kubos, Starr, Rao, \& Price, 1984). Sackeim et al. (1982) reported a greater probability of left hemisphere damage being associated with pathological crying, and right hemisphere damage being associated with pathological laughter.

More recent studies have also provided support for a Bi-Hemispheric Model. For example, massage therapy has been shown to decrease stress and increase left frontal activation on EEG (Diego, Field, Sanders, \& Hernandez-Reif, 2004), suggesting that reducing negative affect or increasing positive affect is related to left frontal activation. Additionally, participants with greater left frontal activation show an increased positive reaction to exercise when compared to those with greater right frontal activation (Petruzzello, Hall, \& Ekkekakis, 2001). Other studies of EEG have suggested that greater left frontal activation is associated with positive affect, whereas greater right frontal activation is associated with negative affect (Davidson, 1995; Tomarken, Davidson, Henriques, 1990). Similarly, positive emotional states have been associated with left hemisphere activity and negative emotional states have been associated with right hemisphere activity in a large collection of studies (Davidson \& Fox, 1982; Davidson \& Henriques, 2000; Davidson, Schwartz, Saron, Bennett, \& Goleman, 1979; Ekman \& Davidson, 1993; Ekman, Davidson, \& Friesen, 1990; Fox \& Davidson, 1988; Lee et al., 2004; Reuter-Lorenz \& Davidson, 1981; Schaffer, Davidson, \& Saron, 1983; Sutton \& Davidson, 2000; Tomarken, Davidson, Wheeler, \& Doss, 1992; Wheeler, Davidson, \& Tomarken, 1993). For example, when asked to report emotional responses while watching a television program, EEG recordings demonstrated left hemisphere activity during positive emotional states, and right hemisphere activity during negative emotional states (Davidson et al., 1979). Likewise, infants have been observed to yield greater relative left frontal activity in response to viewing happy faces, and greater relative right frontal activity in response to viewing sad faces (Davidson \& Fox, 1982).

\section{3 - Current Experiment}

The current experiment tested the competing predictions of the Right Hemisphere Model of Emotion and the Bi-Hemispheric Model of Emotion using left and right CVA patients. While the Right Hemisphere Model predicted that learning positive and negative affective information would be a function of the right hemisphere, the Bi-Hemispheric Model yielded bidirectional predictions. The Bi-Hemisphere model predicted that left cerebrovascular accident (LCVA) 
would reduce the ability to learn positive information and that right cerebrovascular accident (RCVA) would reduce the ability to learn negative information. Additionally, the BiHemispheric model makes diametrically opposite predictions where positive learning (as assessed by the Affective Auditory Learning Test) would increase left hemisphere function (which will be evaluated using a Dichotic Listening Task), and negative learning would result in an increase in right hemisphere function.

The present experiment aimed to pit the two competing theoretical models against each other in unilateral stroke populations, using a double dissociation approach. This term was first defined by H. L. Teuber in 1955 (Van Orden, Pennington, \& Stone, 2001). Neuropsychology often incorporates double dissociation to distinguish two functionally distinct brain areas from each another, with the purpose being to demonstrate the independence of two or more processes in the brain using lesions or other dysfunction. The current experiment tested two different abilities (lateralized hemispheric activation and emotional learning) across two different lesion locations (left hemisphere and right hemisphere). This approach was based on the expectation that damage in a particular area of the brain should not only impair the functions association with that area, but it should also leave the functions that are not associated with that area relatively intact.

The fundamental basis for the current experiment was that a stroke should limit capacity whereas an affective prime should increase functional capacity. Ultimately, the stroke results in a disability where affective exposure may be therapeutic. Specifically, encouraging findings from clinical research show that positive learning experiences have improved functions such as memory, balance, gait, handwriting, and cardiovascular reactivity to stress (Levy, 2003). In contrast, exposure to negative emotional experiences may further the difficulties that result from brain damage.

The purpose of the current experiment was to examine cerebral laterality, emotion, and cardiovascular functions. Secondly, dynamic cerebral laterality was examined using positive or negative affective learning trials. Positive learning experiences were expected to promote left hemisphere functions, whereas negative learning experiences on the AAVLT were expected to promote right hemisphere functions. Dynamic functional cerebral laterality was assessed using dichotic listening protocol and cardiopulmonary indices of sympathetic tone. The current hypotheses were drawn from the Bi-Hemisphere model, where positive learning is affected by 
LCVA and where positive learning was expected to increase left hemisphere brain function. Additionally, negative learning was expected to decrease left hemisphere brain function.

Dichotic Listening Hypotheses:

1. It was hypothesized that LCVA patients would perform significantly below RCVA patients on processing word sounds.

2. It was hypothesized that CVA location would decrease auditory detection performance in the contralateral ear. Specifically, LCVA patients were expected to perform significantly lower than RCVA patients on right ear detections; and RCVA patients were expected to perform significantly lower than LCVA patients on left ear detections.

3. It was hypothesized that exposure to positive and negative valences would activate the left and right hemispheres respectively. Specifically, exposure to the positive word list from the AAVLT was expected to significantly increase right ear detections; and exposure to the negative word list from the AAVLT was expected to significantly increase left ear detections.

\section{AAVLT Hypotheses:}

4. It was hypothesized that LCVA patients would recall significantly fewer words on the AAVLT than RCVA patients.

5. It was hypothesized that LCVA and RCVA patients would recall more negative and positive words, respectively. Specifically, LCVA patients were expected to recall significantly more negative words from the AAVLT than RCVA patients; and RCVA patients were expected to recall significantly more positive words from the AAVLT than LCVA patients.

Physiological Hypotheses:

6. It was hypothesized that exposure to the positive and negative valences would activate the left and right hemispheres, respectively. Specifically, exposure to the positive word list from the AAVLT was expected to significantly decrease HR and increase $\mathrm{SpO} 2$; and exposure to the negative word list from the AAVLT was expected to significantly increase HR and decrease $\mathrm{SpO} 2$. 


\section{Chapter 2 - Method}

\section{1 - Participants}

Participants consisted of 21 patients undergoing neuropsychological evaluations at a tertiary care medical center. Measures administered were part of a routine neuropsychological battery (Hugdahl, 1995; 2002), which served to establish a baseline level of functioning and to assist other healthcare professionals in treatment planning. Assessments were completed in a private testing room within the rehabilitation unit of the medical center. After a review of medical records, eligible patients were grouped into samples of 11 patients, status post-acute left cerebrovascular accident (LCVA), and 10 patients, status post-acute right cerebrovascular accident (RCVA). Patients included 11 men and 10 women, ages 39 to 88 with a mean age of 73.61. Selection criteria included: men and women with a history of a cerebrovascular accident (CVA); unilateral left- or right-hemisphere pathology; an available post-stroke CT or MRI scan of the head on file; right-handedness by self-report; native English speaker; no history of mental retardation; education through high school or beyond, and no current substance abuse. Patients were required to be able to recognize basic phonemes, as assessed by the initial training trials of the Dichotic Listening Test. Additionally, patients were required to exhibiting a learning curve, or the ability to learn new information (at least three words), as assessed by the Affective Auditory Verbal Learning Test. The research was approved by the Psychology Department Human Subjects Committee and by Virginia Polytechnic Institute and State University's Institutional Review Board.

\section{2 - Apparatus}

Dichotic Listening Test: The Dichotic Listening test is a behavioral test in which two different auditory stimuli are simultaneously presented, one to each ear (Hugdahl, 1995). A computer-synthesized audio file, created by the Kresge Hearing Research Laboratory, of 30 pairs of concurrently voiced consonant vowels (CV's: ba, da, ga, ka, pa, ta) was played for each patient (see Appendix A). This audio file has been used as a dichotic listening test in numerous experiments on laterality and elsewhere (Hugdahl, 1995). Stimuli were presented at about $75 \mathrm{~dB}$ (A Scale; reference value $.002 \mathrm{dynes} / \mathrm{cm}^{2}$ ) via a Memorex MP3851BLK dual channel Boom box using Sony MDR-ZX100 headphones. The interstimulus interval was six seconds. The six CVs were printed as 2-cm, bold, black, upper case Arial font letters on a 96 X $144 \mathrm{~cm}$ choice card 
displayed about $0.5 \mathrm{~m}$ on a desktop in front of the patient. Following the presentation of a pair of CV's, the patient were required to choose one of the six possible choices that he/she heard by pointing to the current stimulus on the card.

Affective Auditory Learning: The Affective Auditory Verbal Learning Test (AAVLT) is a 15 item list learning test comprised of three different word lists differing in affective valence: positive, negative, and neutral (Snyder, Harrison, \& Shenal, 1997; see Appendix B). The lists were adapted from an index of word norms established by Toglia and Battig (1978). The positive word list is comprised of words that were rated the highest in pleaseantness, whereas the negative word list is comprised of words that were rated the lowest in pleasantness. The words were also chosen for equivalency based on how often they occur in the English language. The neutral list is taken from the Rey Auditory Verbal Learning Test (RAVLT; Rey, 1964). The positive list includes words such as "sunset, garden, and beach," while the negative list includes words such as "morgue, murder, and kill." The neutral list consists of words such as "drum," "curtain," and "bell." Instructions for the AAVLT and the three word lists were recorded onto a compact disc. The word lists were recorded at a rate of about one word per second. Following each presentation of a list, the patient was required to recall as many words as he/she can remember. Each list was presented five times with a recall trial after each presentation.

Physiological: Heart Rate (HR) measured in beats per minute (bpm) and Percutaneous Oxygen Saturation (SpO2), using red and infrared light, measured in percentage (\%) of bound hemoglobin (HbO2) were assessed using the Nature Spirit Fingertip Pulse Oximeter (Model 5892). The accuracy of HR is reported to be within $2 \%$ or 2 beats per minute. The accuracy of $\mathrm{SpO} 2$ is reported to be within $2 \%$ for readings between 70 and $99 \%$.

Self-Report: Handedness was assessed using a 4-item Brief Laterality Questionnaire (BLQ) adapted from the 13-item Coren-Porac-Duncan Laterality Test (Coren, Porac, \& Duncan, 1979, see Appendix C). This self-report adaptation utilizes 4 questions to determine handedness including: "Which hand would you use to write with;" "Which eye would you use to look through a telescope;" "Which foot would you use to kick a ball;" and "Which ear would you use to talk on the telephone;"

Depression was assessed using the full length version of the Mood Assessment Scale (MAS; Yesavage, et al., 1983). The MAS is a 30 item self-report questionnaire designed to assess depression in individuals 56 and older, utilizing a Yes/No response format (see Appendix 
D). Questions related to mood such as "Have you dropped many of your activities and interests?" are read aloud to the patient, and the patient gives a verbal response. Total scores of 0-9 indicate a normal mood, scores of 10-19 indicate mild depression, and scores of 20-30 indicate severe depression. The MAS is available in public domain.

\section{3 - Procedure}

During the neuropsychological assessment, patients were administered the BLQ to determine hemibody preference. Heart rate and oxygen saturation were continuously monitored and recorded at predetermined intervals throughout the assessment. Two consecutive readings, about ten seconds apart, were recorded. If HR values differ by ten beats per minute, a third HR reading will be recorded. If SPO2 values differed by ten percent, a third SPO2 reading was recorded.

Baseline. Following placement of the Finger Pulse Oximeter on the middle finger of the left hand, two consecutive HR and SPO2 readings were recorded. Patients were then administered the 30 trial Dichotic Listening Test, taking about three minutes.

A brief training phase was implemented to introduce the dichotic listening procedures. The experimenter read and pointed to each of the six phonemes on the choice card and had the patient repeat each phoneme. Headphones were then be used to present the phonemes and the patient will be instructed to state the phoneme that they heard and to point to the lexical representation on the card. The researcher provided corrective feedback. The patient was required to correctly identify five of the six phonemes to continue participation.

The patient was then told:

"You are about to hear 30 trials of syllables. You will hear a syllable in one ear and another syllable in the opposite ear, and it will sound like two people talking to you at the same time. Your job is to listen very carefully and point to the syllable on the card that you hear most clearly."

All responses were recorded. After 30 trials, taking about three minutes, two consecutive HR and SPO2 readings were recorded. The patient was then administered the neutral list from the AAVLT, and asked to recall as many words as he/she could remember. Presentation and recall were repeated for a total of five trials, taking about five minutes. Following the Neutral list, the Dichotic Listening Test was administered again. Two consecutive HR and SPO2 readings were recorded again. 
Affective-Exposure. Affective list order was counterbalanced with patients receiving either the Positive list before the Negative list (see Appendix E) or the Negative list before the Positive word list (see Appendix F) from the AAVLT. After administration of the first affective word list, two consecutive HR and SPO2 readings were recorded, followed by administration of the Dichotic Listening Test. Again, two consecutive HR and SPO2 readings were recorded. Next patients were administered the second affective word list, followed by two consecutive HR and SPO2 readings. A final Dichotic Listening Test was administered, followed by two final consecutive HR and $\mathrm{SPO} 2$ readings.

Post Affective-Exposure. Patients were administered the MAS at the end of the assessment. 


\section{Chapter 3 - Results}

Before testing the hypotheses, descriptive statistics were performed on each variable to identify any missing data or outliers. Of the $21 \mathrm{CVA}$ patients, one patient was unable to finish the testing session, and therefore had missing data. All $21 \mathrm{CVA}$ patients were included in the analyses and pairwise deletion was used when needed. The absolute values of the skewness and kurtosis statistics for all dependent variables were less than two. Additionally groups were compared across demographic variables to ensure homogeneity. Interestingly, LCVA patients from this experiment had significantly more years of education $(M=14.27, S D=2.83)$ than RCVA patients $(M=11.10, S D=4.04), t(19)=2.10, p<0.05$. In order to ensure that education did not enable participants to perform better on Verbal Learning or Dichotic Listening, bivariate correlations between years of education and total number of words/detections were performed. Correlations were not significant indicating that those with prior higher education did not remember more neutral words $r(19)=.24, p=0.29$ or detect more phonemes $r(19)=-.01, p=$ 0.97 .

Self-Report Questionnaire Analysis

To determine if groups (LCVA, and RCVA) would differ on reported levels of depression, an independent t-test was performed to analyze the MAS data. LCVA patients $(M=$

9.36, $S D=5.41)$ did not significantly differ from RCVA patients $(M=9.44, S D=4.95)$ on Mood Assessment Scale scores, $t(19)=-0.03, p=0.97$. Thus LCVA and RCVA patients did not differ on reported levels of depression.

Dichotic Listening Analyses

Separate three factor mixed design ANOVAs were performed under a General Linear Model framework to analyze the dichotic listening data. The ANOVAs for Dichotic Listening included the following factors: a fixed effect of group (LCVA and RCVA), and repeated measures for affect (Neutral, Positive, and Negative word lists from AAVLT), and condition (Pre and Post word list). All post hoc pairwise comparisons among the means were made using Tukey's HSD test (Winer, 1971) with the a priori $p \leq .05$. 
An ANOVA was performed for total detections on the dichotic listening test. Results showed that CVA group did not have a significant effect on number of detections, $F(1,19)=$ 1.03, $p=0.32$. Specifically, LCVA patients $(M=13.58, S D=5.96)$ did not perform significantly below RCVA patients $(M=15.80, S D=4.30)$ on processing word sounds.

Independent ANOVAs were performed on three dependent variables obtained during the dichotic listening test (laterality index (LI) score, number of correctly identified stimuli in the left ear, and number of correctly identified stimuli in the right ear. LI scores were calculated using the following formula: $\mathrm{LI}=(\mathrm{pR}-\mathrm{pL}) /(\mathrm{pR}+\mathrm{pL})$, where $\mathrm{pR}$ is the proportion of correctly identified right ear stimuli and $\mathrm{pL}$ is the proportion of correctly identified left ear stimuli. The LI score can range from +1 (perfect left ear advantage) to -1 (perfect right ear advantage). For LI scores, a nonsignificant trend was observed where LCVA patients $(M=.04, S D=0.36)$ demonstrated little or no left ear advantage and RCVA patients $(M=-.27, S D=0.42)$ demonstrated a slight right ear advantage, $F(1,19)=5.15, p=0.0584$. Further within groups comparisons of this trend revealed a significant main effect of ear for RCVA patients. Specifically, RCVA patients had significantly more right ear detections $(M=10.72, S D=5.81)$, than left ear detections $(M=5.08, S D=2.67)$ across all trials of the dichotic listening test, $F(1$, $9)=4.06, p<0.05$. In contrast, LCVA patients did not significantly differ between the number of left ear detections $(M=7.62, S D=3.99)$ and right ear detections $(M=7.07, S D=3.71)$, on the dichotic listening test $F(1,10)=0.10, p=0.76$.

For left detections (the number of correctly identified stimuli presented at the left ear averaged across the six administrations) CVA groups did not significantly differ, $F(1,19)=3.16$, $p=0.09$. Thus, RCVA patients $(M=5.08, S D=2.67)$ did not perform significantly lower on left ear detections than LCVA patients $(M=7.62, S D=3.99)$. Additionally, for right detections (the number of correctly identified stimuli presented at the left ear averaged across the six administrations), LCVA $(M=7.07, S D=3.71)$ and RCVA $(M=10.72, S D=5.81)$ patients did not significantly differ, $F(1,19)=3.12, p=0.09$.

Results also found that affect did not have a significant effect on right ear detections, $F(2,38)=2.87, p=0.0699$; or left ear detections, $F(2.38)=0.85, p=0.44$. Specifically, right ear detections were not significantly increased for CVA patients following exposure to the positive word list (pre-positive $M=9.10, S D=5.73$; post-positive $M=8.75, S D=4.83$ ). Similarly, left 
ear detections were not significantly increased for CVA patients following exposure to the negative word list (pre-negative $M=6.25, S D=3.70$; post-negative $M=6.30, S D=4.33$ ). Auditory Affective Verbal Learning Analyses

For hypotheses regarding AAVLT performance, separate three factor mixed design ANOVAs were performed under a General Linear Model framework to analyze the AAVLT data. The ANOVA for number of words recalled included the following factors: a fixed effect of group (LCVA and RCVA), and repeated measures for affective valence (neutral, positive, and negative), and trial (verbal learning trials 1-5). All post hoc pairwise comparisons among the means were made using Tukey's HSD test (Winer, 1971) with the a priori $p \leq .05$.

Results showed that LCVA patients $(M=5.44, S D=2.78)$ did not recall significantly fewer words than RCVA patients $(M=5.26, S D=2.15), F(1,19)=0.00, p=0.95$. This suggests that CVA location did not have a significant effect on number of words recalled across the five trials. Similarly, results did not reveal a significant group by affect interaction when averaging across all five trials of the AAVLT. Thus, LCVA patients $(M=5.54, S D=2.70)$ did not recall significantly more negative words than RCVA patients $(M=5.14, S D=2.34)$, and RCVA patients $(M=5.08, S D=1.91)$ did not recall significantly more positive words than left CVA patients $(M=5.64, S D=2.47), F(1,19)=0.62, p=0.54$.

However, a significant main effect of affect was found for number of words recalled on trial 1, where CVA patients recalled significantly more positive words $(M=4.30, S D=1.78)$, than negative $(M=3.60, S D=1.53)$ or neutral words $(M=3.57, S D=1.69), F(2,38)=4.19, p<$ 0.05 . When parsed by group, LCVA patients recalled significantly more positive words $(M=$ $4.80, S D=1.87)$ than negative $(M=3.90, S D=1.66)$ or neutral words $(M=3.45, S D=1.69)$ on trial $1, F(1,10)=4.52, p<0.05$. However, RCVA patients did not exhibit significant differences in recall ability based on affect, recalling a similar number of positive $(M=3.80, S D=1.62)$, negative $(M=3.30, S D=1.42)$, and neutral words $(M=3.70, S D=1.77)$ on trial $1, F(2,9)=$ $0.76, p=0.48$. It is worth noting that a significant main effect of trial was found, where CVA patients generally recalled significantly more words on subsequent trials of the AAVLT, thereby exhibiting a learning curve, $F(4,80)=23.06, p<0.001$ (see Figure 1).

In order to test for primacy and recency effects, a fourth factor for location was added to the mixed design ANOVA was used under a GLM framework. The ANOVA for primacy and recency included the following factors: a fixed effect of group (LCVA and RCVA), and repeated 
measures for affective valence (Neutral, Positive, and Negative word lists from AAVLT), trial (trial 1, trial 2, trial 3, trail 4, and trial 5 of the AAVLT), and word location (beginning of the list, middle of the list, end of the list). Results indicated a significant main effect of word location, in which CVA patients recalled more words from the end $(M=2.12, S D=1.44)$ and beginning of the list $(M=2.03, S D=1.36)$, than from the middle of the list $(M=1.20, S D=1.13)$ when averaged across all trials, $F(2,40)=12.57, p<0.001$. However, a significant group by location interaction was found, $F(1,19)=4.22, p<0.05$, wherein LCVA patients recalled significantly more words from the end of the list $(M=2.47, S D=1.22)$, than from the beginning $(M=1.83$, $S D=1.39)$, and significantly more words from the beginning than from the middle $(M=1.08$, $S D=1.17)$ of the list, $F(2,8)=4.22, p<0.05$. In contrast, RCVA patients recalled significantly more words at the beginning of the list $(M=2.23, S D=1.30)$ than the middle $(M=1.32, S D=$ 1.06), but not significantly more than the end $(M=1.77, S D=1.56)$ of the list, $F(2,7)=4.55, p<$ 0.05 .

While there was not a significant group by affect by location interaction present, $F(1,8)=$ $1.41, p=0.24$, and there was not a significant affect by location interaction among LCVA patients, $F(2,4)=1.12, p=0.36$, there were notable differences in primacy and recency effects across the various affective conditions of the AAVLT. On the neutral list trials, LCVA patients recalled more words from the end $(M=2.47, S D=1.36)$ than beginning $(M=1.60, S D=1.36)$ or middle $(M=0.96, S D=1.22)$ of the list, $F(2,10)=10.51, p<0.001$. Similarly, on the positive list trials, LCVA patients recalled more words from the end $(M=2.66, S D=1.22)$ than beginning $(M=1.78, S D=1.36)$ and from the beginning than middle $(M=1.20, S D=1.11), F(2$, $9)=6.53, p<0.01$. On the negative list trials, LCVA patients recalled more words from the end $(M=2.28, S D=1.05)$ and beginning $(M=2.14, S D=1.43)$ than the middle $(M=1.10, S D=$ 1.99) of the list, $F(2,9)=7.81, p<0.01$. Thus LCVA patients exhibited a recency effect regardless of word affect, and exhibited a primacy effect that varied with affect.

For RCVA patients, there was a significant affect by location interaction present, $F(2,4)=$ 5.06, $p<0.01$. On neutral list trials, there were no significant differences in number of words recalled at the beginning $(M=2.20, S D=1.32)$, middle $(M=1.28, S D=0.97)$, or end $(M=2.06$, $S D=1.35)$ of the list for RCVA patients, $F(2,9)=2.45, p=0.11$. However, RCVA patients recalled more positive words from the end $(M=2.24, S D=1.90)$ and beginning $(M=1.98, S D=$ 1.33) than the middle $(M=1.06, S D=0.98)$ of the list, $F(2,9)=6.00, p<0.05$, and recalled 
more negative words from the beginning $(M=2.52, S D=1.39)$ and middle $(M=1.62, S D=$ 1.18)of the list than from the end $(M=1.00, S D=1.05)$ of the list, $F(2,9)=6.52, p<0.01$. In summation, RCVA patients did not exhibit a recency effect for neutral information, while positive affective information caused a recency effect and negative affective information caused a primacy effect.

\section{Physiological Analyses}

Separate three factor mixed design ANOVAs were performed under a General Linear Model framework to analyze the $\mathrm{HR}$ and $\mathrm{SpO} 2$ data as related to AAVLT exposure. The ANOVAs included the following factors: a fixed effect of group (LCVA, RCVA, and no CVA), and repeated measures for affect (Neutral, Positive, and Negative word lists from AAVLT), and condition (Pre and Post word list. All post hoc pairwise comparisons among the means were made using Tukey's HSD test (Winer, 1971) with the a priori $p \leq .05$.

Results of the ANOVA for HR found a significant affect by condition (pre-AAVLT/postAAVLT) interaction, $F(2,38)=6.34, p<0.01$, where CVA patients showed a decrease in HR from pre-neutral list $(M=79.62, S D=16.16)$ to post-neutral list $(M=77.19, S D=14.20)$, whereas HR did not significantly differ between pre- $(M=76.28, S D=14.55)$ and post-positive exposure $(M=77.23, S D=15.21)$, or between pre- $(M=77.19, S D=16.29)$ and post-negative exposure $(M=77.15, S D=16.08)$.

Between groups comparisons did not reveal significant differences in heart rate following affective exposure. Following exposure to the Neutral trials, the heart rate of LCVA patients ( $M$ $=78.32, S D=14.44)$ did not significantly differ from that of RCVA patients $(M=75.95, S D=$ $14.60), F(1,18)=0.26, p=0.62$. Likewise, the heart rate of LCVA patients $(M=79.00, S D=$ 15.68) did not significantly differ from that of RCVA patients $(M=75.45, S D=15.35)$ following exposure to Positive trials, $F(1,19)=0.14, p=0.71$. Similarly, the heart rate of LCVA patients $(M=77.25, S D=15.71)$ did not significantly differ from that of RCVA patients $(M=$ $77.05, S D=17.29)$ following exposure to Negative trials, $F(1,18)=0.00, p=0.98$.

When further assessed within groups, the heart rate among LCVA patients significantly decreased from pre-neutral $(M=82.05, S D=15.71)$ to post-neutral $(M=78.32, S D=14.44)$, $F(1,10)=8.65, p<0.05$, but did not significantly differ from pre-positive $(M=77.65, S D=$ $15.34)$ to post-positive $(M=79.00, S D=15.68), F(1,9)=1.36, p=0.27$, or from pre-negative $(M$ $=78.45, S D=17.28)$ to post-negative $(M=77.25, S D=15.71), F(1,9)=0.95, p=0.36$. Heart 
rate levels among RCVA patients did not significantly differ from pre-neutral $(M=76.95, S D=$ 17.06) to post-neutral $(M=75.95, S D=14.60), F(1,9)=1.08, p=0.33$, from pre-positive $(M=$ $74.90, S D=14.39)$ to post-positive $(M=75.45, S D=15.35), F(1,9)=1.79, p=0.21$, or from pre-negative $(M=75.93, S D=16.06)$ to post-negative $(M=77.05, S D=17.29), F(1,9)=1.78, p$ $=0.21$. Graphical comparisons suggested a group by affect by condition interaction may be present; however, the mixed ANOVA was nonsignificant, $F(2,19)=2.07, p=0.14$ (see Figure 2).

Results of the ANOVA for SpO2 found that pulse oxygen saturation did not significantly differ following exposure to AAVLT affective conditions (neutral, positive, negative), $F(2,36)=$ $0.47, p=0.63$. Thus pulse oxygen saturation levels among all CVA patients did not significantly differ from pre-neutral $(M=95.52, S D=2.15)$ to post-neutral $(M=95.69, S D=2.68)$, from prepositive $(M=95.52, S D=1.95)$ to post-positive $(M=95.95, S D=1.66)$, from pre-negative $(M=$ 95.35, $S D=1.91)$ to post-negative $(M=96.15, S D=1.49)$, or across the affective valences of the AAVLT.

Between groups comparisons revealed a significant difference in pulse oxygen saturation levels following affective exposure. Following exposure to the Neutral trials, the pulse oxygen saturation levels of LCVA patients $(M=95.77, S D=3.32)$ did not significantly differ from that of RCVA patients $(M=95.60, S D=1.93), F(1,19)=0.02, p=0.89$. Similarly, the SpO2 of LCVA patients $(M=96.40, S D=1.24)$ did not significantly differ from that of RCVA patients $(M=95.90, S D=1.73)$ following exposure to Negative trials, $F(1,18)=0.55, p=0.47$. However, the SpO2 of LCVA patients $(M=76.70, S D=1.38)$ was significantly higher than that of RCVA patients $(M=95.20, S D=1.64)$ following exposure to Positive trials, $F(1,18)=4.92$, $p<0.05$.

When further assessed within groups, the pulse oxygen saturation levels of LCVA patients did not significantly differ following exposure to AAVLT affective conditions. Pulse oxygen saturation levels among LCVA patients did not significantly differ from pre-neutral $(M=$ $96.13, S D=2.39)$ to post-neutral $(M=95.77, S D=3.32), F(1,10)=0.58, p=0.32$, from prepositive $(M=96.00, S D=1.99)$ to post-positive $(M=96.70, S D=1.38), F(1,9)=4.16, p=0.07$, or from pre-negative $(M=95.85, S D=1.97)$ to post-negative $(M=96.40, S D=1.24), F(1,9)=$ $1.22, p=0.30$. However, pulse oxygen saturation levels among RCVA patients significantly increased from pre-neutral $(M=94.85, S D=1.72)$ to post-neutral $(M=95.60, S D=1.93), F(1,9)$ 
$=13.97, p<0.001$, and also from pre-negative $(M=94.85, S D=1.81)$ to post-negative $(M=$ 95.90, $S D=1.73), F(1,9)=18.99, p<0.01$, while no significant change was found from prepositive $(M=95.05, S D=1.89)$ to post-positive $(M=95.20, S D=1.64), F(1,9)=0.27, p=0.62$. Graphical comparisons suggested a group by affect by condition interaction may be present; however, the mixed ANOVA was nonsignificant, $F(2,19)=2.17, p=0.13$ (see Figure 3). 


\section{Chapter 4 - Discussion}

The current experiment was designed to evaluate the effects of unilateral CVA location and exposure to affective verbal learning on cerebral activation and cardiopulmonary functioning. Patients consisted of two groups (LCVA and RCVA) that completed the Dichotic Listening Test and the Affective Auditory Verbal Learning Test.

It was hypothesized (1) that LCVA patients would perform significantly below RCVA patients on processing word sounds. Results revealed that CVA group did not have a significant effect on number of detections, thus LCVA patients did not perform below RCVA patients when processing word sounds on the Dichotic Listening Test. This is in contrast to literature that suggests left hemisphere dysfunction results in greater language deficits due to the left hemisphere's widely known role in processing auditorally-presented verbal information (Mondor \& Bryden, 1992; Bryden, Free, Gagne, \& Groff, 1991; Ley \& Bryden, 1982). This discrepancy is not better explained by the possibility of compensation through the contralateral ear, as LCVA patients did not demonstrate a unilateral ear advantage. One possible explanation is the higher education levels found in LCVA patients may have acted as a protective factor for language abilities, yet this has not been specifically evidenced in the literature.

It was also hypothesized (2) that CVA location would decrease auditory detection performance in the contralateral ear (LCVA patients were expected to perform significantly lower than RCVA patients on right ear detections; and RCVA patients were expected to perform significantly lower than LCVA patients on left ear detections). This was not confirmed as CVA patients did not significantly differ in number of left or right ear detections. This is in contrast with the widely known anatomical distribution that each hemisphere is responsible for the functions of the contralateral ear. Possible reasons for not finding this effect could be variability introduced by patients with more anterior or posterior CVA's which may leave the functions of the contralateral ear intact. Another explanation is the Dichotic Listening Test has been reported to be a somewhat conservative measure of hemispheric differences due to the presence of ipsilateral bifurcations associated with audition (Shenal \& Harrison, 2003), which may allow for right ear detections despite damage to the left hemisphere and vice versa. Similarly, it has been 
purported that the auditory modality has sufficient redundancy built into the cerebral hemispheres and the brainstem to provide some resistance to a complete hemispatial loss of this modality (Harrison, in press; see also Munkong \& Juang, 2008).

While between groups differences were not indicative of decreased auditory detection following unilateral CVA, results within groups yielded some support. Results found RCVA patients had significantly more right ear detections than left ear detections across all trials of the dichotic listening test, whereas LCVA patients did not significantly differ between the number of left ear detections and right ear detections. It has been reported that healthy individuals typically exhibit more right ear detections than left ear detections on the Dichotic Listening Test (Shenal $\&$ Harrison, 2003). Therefore, results suggest both groups may have exhibited decreased auditory detection abilities in the ear contralateral to CVA location, wherein LCVA patients did not exhibit increased right ear detections and RCVA patients exhibited a right ear detection bias.

It was also hypothesized (3) that exposure to positive and negative valences would activate the left and right hemispheres, respectively. However, affect did not have a significant effect on right ear detections or left ear detections. This is consistent with findings from previous research wherein cognitive affective stressors did not yield increased right hemisphere activation as measure by left ear detections (Shenal \& Harrison, 2003). Other experiments have found significant effects of physiological stressors on ear detections (Demaree \& Harrison, 1997). This suggests that the Dichotic Listening Test may not be sensitive enough to fully detect the subtle cognitive affective stress provided by the AAVLT.

It was hypothesized (4) that LCVA patients would recall significantly fewer words on the AAVLT than RCVA patients. CVA location did not have a significant effect on number of words recalled across the five trials. While it was expected that LCVA patients would exhibit a deficit in word recall based on the verbal nature of the task, research using the California Verbal Learning Test has found that RCVA patients are also likely to have difficulty on verbal recall tasks (Welte, 1993).

It was also hypothesized (5) that LCVA and RCVA patients would recall more negative and positive words, respectively. Results did not reveal a significant group by affect interaction when averaging across all five trials of the AAVLT. Thus, LCVA patients did not recall significantly more negative words than RCVA patients, and RCVA patients did not recall significantly more positive words than left CVA patients. While differences were not found 
across all trials, a significant main effect of affect was found for words recalled on trial 1, where CVA patients recalled significantly more positive words, than negative or neutral words. When parsed by group, LCVA patients recalled significantly more positive words than negative or neutral words on trial 1. However, RCVA patients did not exhibit significant differences in recall ability based on affect, and recalled a similar number of positive, negative, and neutral words on trial 1. The increase on positive words for LCVA patients suggests that they are able to increase learning ability through positive information, but only while the information is novel enough to have an emotional reaction (see Table 4 for the number of positive, negative, \& neutral words recalled for each trial by each group). These results alone do not lend more support to a single model of emotion as the Bi-Hemisphere Model of Emotion would posit that the positive affective information activated the left-hemisphere, thereby improving the learning ability in LCVA patients, whereas the Right Hemisphere Model of Emotion would posit that the positive affective information activated the right-hemisphere, which was damaged in RCVA patients, who were unable to benefit from activation effects.

Perhaps another finding worth noting is that a significant main effect of trial was found, where CVA patients generally recalled significantly more words on subsequent trials of the AAVLT, thereby exhibiting a learning curve. LCVA patients recalled significantly more words on trial 1 of the positive list than on trial 1 of other lists and also more than RCVA patients. However, RCVA patients reached maximum number of negative words recalled on trial 3, whereas LCVA patients recalled their highest number of negative words on trial 5. Taken together, these results indicate that LCVA patients can learn positive information relatively easily, whereas RCVA patients can learn negative information relatively quickly. This differential effect may highlight a negative emotional bias in the RCVA patients. While this is in contrast to the expected indifference bias of RCVA patients and catastrophic bias of LCVA patients, some research has suggested that negative bias gradually decreases in LCVA patients and gradually increases in RCVA patients across the recovery process (Johnson \& Hartlage, 1997).

With regard to primacy and recency effects, CVA patients recalled more words from the end and beginning of the list, than from the middle of the list when averaged across all trials. However, a significant group by location interaction was found wherein LCVA patients recalled significantly more words from the end of the list, than from the beginning, and significantly 
more words from the beginning than from the middle of the list. In contrast, RCVA patients recalled significantly more words at the beginning of the list than the middle, but not significantly more than the end.

When comparing the effects of affect, LCVA patients exhibited an increased combined primacy/recency effect for negative words and a recency effect for positive words, whereas RCVA patients a primacy effect for negative words and a recency effect for positive words.

Overall these results are consistent with previous experiments in healthy individuals (Demaree \& Everhart, 2004; Demaree, Shenal, Everhart \& Robinson, 2004; Everhart, Carpenter, Carmona, Ethridge, \& Demaree, 2003; Everhart \& Demaree, 2003; Snyder \& Harrison, 1997, Snyder, Harrison, \& Shenal, 1998) suggesting that CVA did not negate the effects of affect on processing verbal information.

It was hypothesized (6) that exposure to the positive and negative valences would activate the left and right hemispheres, respectively. Specifically, exposure to the positive word list from the AAVLT was expected to significantly decrease HR and increase SpO2; and exposure to the negative word list from the AAVLT was expected to significantly increase HR and decrease $\mathrm{SpO}$ 2. CVA patients showed a decrease in HR from pre-neutral list to post-neutral list, whereas HR did not significantly differ between pre- and post-positive exposure, or between pre- and post-negative exposure. This suggests that the neutral trial of the AAVLT had a parasympathetic response (left-hemisphere activation), as would be expected by an affectively neutral verbal task.

Between groups comparisons did not reveal significant differences in HR at baseline or following any of the AAVLT conditions. However, when further assessed within groups, the mean HR of LCVA patients significantly decreased from pre-neutral to post-neutral, but did not significantly differ from pre- to post-positive, or from pre- to post-negative. HR levels among RCVA patients did not significantly differ from pre- to post- neutral, negative, or positive. Graphical comparisons suggested a group by affect by condition interaction may be present. Despite this being nonsignificant, such an interaction would require a larger sample size of CVA patients.

Pulse oxygen saturation levels among all CVA patients did not significantly differ from pre-neutral to post-neutral from pre-positive to post-positive, from pre-negative to post-negative, or across the affective valences of the AAVLT. However, between groups comparisons revealed 
a significant difference in pulse oxygen saturation levels following affective exposure. While the pulse oxygen saturation levels of LCVA patients did not significantly differ from that of RCVA patients following neutral or negative trials, the $\mathrm{SpO} 2$ of LCVA patients was significantly higher than that of RCVA patients following exposure to Positive trials. When taken alone, this might suggest that the positive affective information activated the left hemisphere and increased parasympathetic tone in patients with left hemisphere weakness, which is consistent with previous research that suggests that positive information may serve to enhance functioning in geriatric individuals (Levy, 2003).

Yet, when further assessed within groups, the pulse oxygen saturation levels of LCVA patients did not significantly differ following exposure to AAVLT affective conditions. Instead, pulse oxygen saturation levels among RCVA patients significantly increased from pre- to postneutral and also from pre- to post-negative, while no significant change was found from pre- to post-positive. These findings suggest that patients with right-hemisphere weakness experienced left-hemisphere activation (parasympathetic response) following exposure to negative affective information, which would typically be expected to activate the right hemisphere and decrease parasympathetic tone. These findings may be the result of bi-hemispheric activation to negative emotion wherein RCVA patients were unable to exhibit the expected sympathetic response due to a damaged right-hemisphere. Results might also lend support for a dynamic reactive process (parasympathetic tone) given a weakened sympathetic response system. Previous research has shown the effect of the affective lists on sympathetic response to be dynamic and stress dependent (Shenal, Rhodes, and Harrison, 2000). When graphed, there appears to be a group (LCVA, RCVA) by affect (Pos, Neg, Neut) by condition (pre, post) interaction. As with the HR data, such an interaction would require a larger sample size to be detectable with sufficient power.

As mentioned earlier, a noteworthy finding was that LCVA patients had more years of education than RCVA patients. While LCVA patients had more mean years of education than RCVA patients, the two groups did not perform differently on word recall or learning across trials. Currently there appears to be little or no research looking at the relationship between education and stroke risk. While the current study does not aim to investigate etiological differences across CVA patients, future research may want to address education levels as a possible predictor of CVA location. 
Results revealed that LCVA and RCVA patients did not differ on reported levels of depression. While this finding does not readily lend support to the Right Hemisphere or the Bihemispheric models of emotion, it is more incongruent with the $\mathrm{Bi}$-hemispheric model of emotion given that depression did not tend to result from lateralized hemisphere dysfunction. This finding is most consistent with literature suggesting that depression can result from dysfunction in either hemisphere (Shenal, Harrison, \& Demaree, 2003).

One limitation of this study was the inclusion of patients with anterior and posterior unilateral stroke locations, which may add variability in regards to the functional cerebral systems affected by the stroke (Shenal, Harrison, \& Demaree, 2003). Future research may want to exclude such patients or sample enough patients to make group comparisons among anterior, posterior, and middle cerebral artery strokes. Additional limitations included the small group sizes in the current sample, despite previous research's ability to find the effects of hemispheric dysfunction on measures of cerebral laterality with relatively small group sizes (Mollet \& Harrison, 2007). Another consideration is the current study included both male and female patients. Even though the current study screened for laterality with the BLQ, previous research has reported laterality to be greater in males than females (Hines, 1990).

While the findings of this study largely did not support the hypotheses, there were noteworthy contributions to the effects of unilateral CVA on hemispheric activation and emotion. Overall it would appear that patients with CVA are borderline-mildly depressed, regardless of stroke location. Also, CVA patients also exhibited a learning curve and an ability to recall 3-5 pieces of verbal information on average, which may help inform the rehabilitation therapist. Additionally, LCVA patients did not show the typical right ear advantage that healthy individuals exhibit on the dichotic listening test, whereas RCVA patients showed an exaggerated right ear advantage. Additionally, RCVA patients appeared more affected on the AAVLT as they exhibited a primacy effect, whereas LCVA patients exhibited a recency effect, which is more common in healthy individuals. Taken together these results lend partial support to the hypotheses of the Bi-Hemispheric Model of Emotion as evidenced by the dynamically opposite effects in these groups which appears to reflect opposing cerebral processes. Future research may want to consider studying hemispheric activation through more reactive measures such as blood pressure or galvanic skin response as dichotic listening appeared to be less sensitive in detecting affective changes than pulse oxygen saturation. A further understanding of cardiovascular 
reactivity and learning abilities in CVA patients could prove useful to rehabilitation of this population. 


\section{References}

Ahern, G. L., \& Schwartz, G. E. (1985). Differential lateralization for positive and negative emotion in the human brain: EEG spectral analysis. Neuropsychologia, 23(6), 745-756. doi: 10.1016/0028-3932(85)90081-8

Babinksi, J. (1914). Contributions of cerebral hemispheric organization in the study of mental troubles. Review Neurologique, 27, 845-848.

Banich, M. T., Stolar, N., Heller, W., \& Goldman, R. B. (1992). A deficit in right-hemisphere performance after induction of a depressed mood. Neuropsychiatry, Neuropsychology, and Behavioral Neurology, 5, 20-27.

Borod, J. C., (1992). Interhemispheric and intrahemispheric control of emotion: A focus on unilateral brain damage. Journal of Consulting and Clinical Psychology, 60(3), 339-348. doi: 10.1037/0022-006X.60.3.339

Borod, J. C. (1993). Cerebral mechanisms underlying facial, prosodic, and lexical emotional expression: A review of neuropsychological studies and methodological issues. Neuropsychology, 7(4), 445-463. doi: 10.1037/0894-4105.7.4.445

Borod, J. C., Andelman, F., Obler, L. K., Tweedy, J. R., \& Welkowitz, J. (1992). Right hemisphere specialization for the identification of emotional words and sentences: Evidence from stroke patients. Neuropsychologia, 30(9), 827-844. doi: 10.1016/00283932(92)90086-2

Borod, J. C., Bloom, R. L., Brickman, A. M., Nakhutina, L., \& Curko, E. A. (2002). Emotional processing deficits in individuals with unilateral brain damage. Applied Neuropsychology, 9(1), 23-36. doi: 10.1207/S15324826AN0901_4

Borod, J. C, Caron, H, \& Koff, E. (1981). Asymmetry in positive and negative facial expressions: Sex differences. Neuropsychologia, 19(6), 819-824. doi: 10.1016/00283932(81)90095-6

Borod, J. C., Cicero, B. A., Obler, L. K., Welkowitz, J., Erhan, H. M., Santschi, C.,...Whalen, J. R. (1998). Right hemisphere emotional perception: Evidence across multiple channels. Neuropsychology, 12(3), 446-458. doi: 10.1037/0894-4105.12.3.446 
Borod, J. C., Haywood, C. S., \& Koff, E. (1997). Neuropsychological aspects of facial asymmetry during emotional expression: A review of the normal adult literature. Neuropsychology Review, 7(1), 41-60.

Borod, J. C, Koff, E, \& Buck, R. (1986). The neuropsychology of facial expression in normal and brain-damaged subjects. In P. Blanck, R. Buck, \& R. Rosenthal (Eds.), Nonverbal communication in the clinical context (pp. 196-222). University Park, PA: Pennsylvania State University Press.

Borod, J. C, Koff, E, \& Caron, H. (1983). Right hemispheric specialization for the expression and appreciation of emotion: A focus on the face. In E. Perecman (Ed.), Cognitive processing in the right hemisphere (pp. 83-110). New York: Academic Press.

Borod, J. C., Rorie, K. D., Pick, L. H., Bloom, R. L., Andelman, F., Campbell, A. L.,...Sliwinksi, M. (2000). Verbal pragmatics following unilateral stroke: Emotional content and valence. Neuropsychology, 14(1), 112-124. doi: 10.1037/08944105.14.1.112

Borod, J. C., Vingiano, W., \& Cytryn, F. (1988). The effects of emotion and ocular dominance on lateral eye movement. Neuropsychologia, 26(2), 213-220. doi: 10.1016/00283932(88)90075-9

Bostanov, V., \& Kotchoubey, B. (2004). Recognition of affective prosody: Continuous wavelet measures of event-related brain potentials to emotional exclamations. Psychophysiology, 41(2), 259-268. doi: 10.1111/j.1469-8986.2003.00142.x

Bowers, D., Coslett, B., Bauer, R., Speedie, L., \& Heilman, K. M. (1987). Comprehension of emotional prosody following unilateral brain damage: Processing versus distraction defects. Neuropsychologia, 25, 317-328.

Bryden, M. P., Free, T., Gagne, S., \& Groff, P. (1991). Handedness effects in the detection of dichotically-presented words and emotions. Cortex, 229-235.

Bryden, M. P., \& Ley, R. G. (1983). Right-hemispheric involvement in the perception and expression of emotion in normal humans. In K. M. Heilman \& P. Satz (Eds.), Neuropsychology of human emotion (pp. 6-44). New York: Guilford Press.

Bryden, M. P., \& MacRae, L. (1989). Dichotic laterality effects obtained with emotional words. Neuropsychiatry, Neuropsychology, and Behavioral Neurology, 1, 171-176. 
Buchanan, T. W., Lutz, K., Mirzazade, S., Specht, K., Shah, N. J., Zilles, K., \& Jancke, L. (2000). Recognition of emotional prosody and verbal components of spoken language: An fMRI study. Cognitive Brain Research, 9(3), 227-238. doi: 10.1016/S09266410(99)00060-9

Buck, R. (1984). The communication of emotion. New York: Guilford Press.

Carmona, J. E., Holland, A. K., \& Harrison, D. W. (2009). Extending the functional cerebral systems theory of emotion to the vestibular modality: A systematic and integrative approach. Psychological Bulletin, 135(2), 286-302. doi: 10.1037/a0014825

Centers for Disease Control and Prevention (2001). Prevalence of disabilities and associated health conditions among adults: United States, 1999. Morbidity and Mortality Weekly Report, 50, $120-125$.

Coren, S. P., Porac, C., \& Duncan, P. (1979). A behaviorally validated self-report inventory to assess 4 types of lateral preferences. Journal of Clinical Neuropsychology, 1, 55-64.

Davidson, R. J. (1984). Affect, cognition, and hemispheric specialization. In C. E. Izard, J. Kagan, \&R. Zajonc (Eds.), Emotion, cognition, and behavior (pp. 320-365). New York: Cambridge University Press.

Davidson, R. J. (1995). Cerebral asymmetry, emotion, and affective style. In R. J. Davidson \& K. Hughdahl (Eds.), Brain Asymmetry (pp. 361-387). Cambridge: MIT Press.

Davidson, R. J., Ekman, P., Saron, C. D., Senulis, J. A., \& Friesen, W. V. (1990). Approachwithdrawal and cerebral asymmetry: Emotional expression and brain physiology. I. Journal of Personality and Social Psychology, 58(2), 330-341. doi: 10.1037/00223514.58.2.330

Davidson, R. J., \& Fox, N. A. (1982). Asymmetrical brain activity discriminates between positive versus negative affective stimuli in human infants. Science, 218(4578), 12351237. doi: 10.1126/science.7146906

Davidson, R. J., \& Henriques, J. B. (2000). Regional brain function in sadness and depression. In J. C. Borod (Ed.), The neuropsychology of emotion (pp. 269-297). New York: Oxford Press.

Davidson, R. J., Schwartz, G. E., Saron, C., Bennett, J., \& Goleman, D. J. (1979). Frontal versus parietal EEG asymmetry during positive and negative affect. Psychophysiology, 16(2), 202-203. 
Debener, S., Beauducel, A., Nessler, D., Brocke, B., Heilemann, H., \& Kayser, J. (2000). Is resting anterior EEG alpha asymmetry a trait marker for depression? Findings for healthy adults and clinically depressed patients. Neuropsychobiology, 41, 31-37.

Demaree H. A. \& Everhart, D. E. (2004). Healthy high-hostiles: reduced parasympa-thetic activity and decreased sympathovagal flexibility during emotional processing. Personality and Individual Differences. 36(2), 457-69.

Demaree, H. A., Everhart, D. E., Youngstrom, E. A, \& Harrison, D. W. (2005). Brain lateralization of emotional processing: Historical roots and a future incorporating “dominance." Behavioral and Cognitive Neuroscience Reviews, 4(1), 3-20. doi: $10.1177 / 1534582305276837$

Demaree, H. A., Shenal, B. V., Everhart, D. E. \& Robinson, J. L. (2004). Primacy and recency effects found using affective word lists. Cognition and Behavioral Neurology. 17(2), $102-8$.

Demaree, H. A., \& Harrison, D. W. (1997). Physiological and neuropsychological correlates of hostility. Neuropsychologia, 35(10), 1405-1411.

Denny-Brown, D., Meyer, J. S., \& Horenstein, S. (1952). The significance of perceptual rivalry resulting from parietal lesions. Brain, 75(4), 434-471. doi: 10.1093/brain/75.4.432

Diego, M. A., Field, T., Sanders, C., \& Hernandez-Reif, M. (2004). Massage therapy of moderate and light pressure and vibrator effects on EEG and heart rate. International Journal of Neuroscience, 114(1), 31-45. doi: 10.1080/00207450490249446

Dimond, S. J., Farrington, L., \& Johnson, P. (1976) Differing emotional response from right and left hemispheres. Nature, 261(5562), 690-692. doi: 10.1038/261690a0

Ehrlichman, H. (1987). Hemispheric asymmetry and positive-negative affect. In D. Ottoson (Ed.), Duality and unity of the brain (pp.194-206). Hampshire, England: Macmillan.

Ekman, P., \& Davidson, R. J. (1993). Voluntary smiling changes regional brain activity. Psychological Science, 4(5), 342-345. doi: 10.1111/j.1467-9280.1993.tb00576.x

Ekman, P., Davidson, R. J., \& Friesen, W. V. (1990). The Duchenne smile: Emotional expression and brain physiology. II. Journal of Personality and Social Psychology, 58(2), 342-353. doi: 10.1037/0022-3514.58.2.342 
Emerson, C. S., Harrison, D. W., \& Everhart, D. E. (1999). Investigation of receptive affective prosodic ability in school-aged boys with and without depression. Neuropsychiatry, Neuropsychology, and Behavioral Neurology, 12(2), 102-109.

Everhart, D. E., Carpenter, M. D., Carmona, J. E., Ethridge, A. J., \& Demaree, H. A. (2003). Adult sex-related P300 differences during the perception of emotional prosody and facial affect. Psychophysiology, 40, 39-39.

Everhart, D. E., \& Demaree, H. A. (2003). Low alpha power (7.5-9.5 Hz) changes during positive and negative affective learning. Cognitive, Affective, and Behavioral Neuroscience, 3(1), 39-45.

Fleminger, S. (1991). Left-sided Parkinson's disease is associated with greater anxiety and depression. Psychological Medicine, 21, 629-638.

Foster, P. S., Drago, V., Ferguson, B. J., \& Harrison, D. W. (2008). Cerebral moderation of cardiovascular functioning: A functional cerebral systems perspective. Clinical Neurophysiology, 119(12), 2846-2854. doi: 10.1016/j.clinph.2008.08.021

Fox, N. A. (1991). If it's not left, it's right. American Psychologist, 46(8), 863-872. doi: 10.1037/0003-066X.46.8.863

Fox, N. A., \& Davidson, R. J. (1988). Patterns of brain electrical activity during facial signs of emotion in 10-month-old infants. Developmental Psychology, 24(2), 230-236. doi: 10.1037/0012-1649.24.2.230

George, M. S., Parekh, S. I., Rosinsky, N., Ketter, T. A., Kimbrell, T. A., Heilman, K. M., \& Herscovitch, P. (1996). Understanding emotional prosody activates right hemisphere regions. Archives of Neurology, 53(7), 655-670.

Goldstein, K. (1939). The organism. New York, NY: American Books.

Green, J. B., \& Hamilton, W. J. (1976). Anosagnosia for hemiplegia: Somatosensory evoked potential studies. Neurology, 26(12), 1141-1144.

Harrison, D. W. (in press). Brain asymmetry and neural systems: Neuroscience foundations for clinical neuropsychology. New York, NY: Springer Publishing Company.

Harrison, D. W., \& Gorelczenko, P. M. (1990). Functional asymmetry for facial affect perception in high and low hostile men and women. International Journal of Neuroscience, 55(2-4), 89-97. doi: 10.3109/00207459008985954 
Heilman, K. M. (1982). Amnestic disturbance following the left dorsomedial nucleus of the thalamus. Neuropsychologia, 20(5), 597-604. doi: 10.1016/0028-3932(82)90033-1

Heilman, K. M. (1997). The neurobiology of emotional experience. Journal of Neuropsychiatry and Clinical Neuroscience, 9(3), 439-448.

Heilman, K. M., \& Bowers, D. (1990). Neuropsychological studies of emotional changes induced by right and left-hemisphere lesions. In N. Stein, B. Leventhal, \& T. Trabasso (Eds.), Psychological and Biological Approaches to Emotion (pp. 97-114). Hillsdale, NJ: Lawrence Erlbaum.

Heilman, K. M., Bowers, D., \& Valenstein, E. (1985). Emotional disorders associated with neurological diseases. In K. M. Heilman \& E. Valenstein (Eds.), Clinical Neuropsychology (pp. 377-402). New York: Oxford University Press.

Heilman, K. M., Bowers, D., \& Valenstein, E. (1993). Emotional disorders associated with neurological diseases. In: Heilman, K. M., and Valenstein, E. (Eds.), Clinical Neuropsychology, Oxford University Press, New York, pp. 461-498.

Heilman, K. M., \& Gilmore, R. L. (1998). Cortical influences in emotion. Journal of Clinical Neurophysiology, 15(5), 409-423.

Heilman, K. M., Scholes, R., \& Watson, R. T. (1975). Auditory affective agnosia. Disturbed comprehension of affective speech. Journal of Neurology, Neurosurgery, and Psychiatry, 38(1), 1018-1020. doi: 10.1136/jnnp.38.1.69

Heilman, K. M., Schwartz, H. D., \& Watson, R. T. (1978). Hypoarousal in patients with the neglect syndrome and emotional indifference. Neurology, 28(3), 229-232.

Heilman, K. M., \& Van Den Abell, T. (1979). Right hemisphere dominance for mediating cerebral activation. Neuropsychologia, 17(3-4), 315-321. doi: 10.1016/00283932(79)90077-0

Heilman, K. M., \& Van Den Abell, T. (1980). Right hemisphere dominance for attention: The mechanism underlying hemispheric asymmetry of inattention. Neurology, 30, 327-330.

Heilman, K. M., Watson, R. T., \& Valenstein, E. (2003). Neglect and related disorders. In K. M. Heilman \& E. Valenstein (Eds.), Clinical neuropsychology (pp. 447-478). New York, NY: Oxford University Press. 
Heller, W. (1993). Neuropsychological mechanisms of individual differences in emotion, personality, and arousal. Neuropsychology, 7(4), 476-489. doi: 10.1037/08944105.7.4.476

Henriques, J.B., \& Davidson, R.J., (1991). Left frontal hypoactivation in depression. Journal of Abnormal Psychology, 100(4), 535-545. doi: 10.1037/0021-843X.100.4.535

Herridge, M. L., Harrison, D. W., \& Demaree, H. A. (1997). Hostility, facial configuration, and bilateral asymmetry on galvanic skin response. Psychobiology, 25(1), 71-76.

Herridge, M. L., Harrison, D. W., Mollet, G. A., \& Shenal, B. V. (2004).Hostility and facial affect recognition: Effects of a cold pressor stressor on accuracy and cardiovascular reactivity. Brain and Cognition, 55(3), 564-571. doi: 10.1016/j.bandc.2004.04.004

Hines, M. (1990). Gonadal hormones and cognitive development. In Balthazart (Ed.), Hormones, brain, and behavior in vertebrates: 1. Comparative physiology, (pp. 51-63). Basel, Switzerland: Karger.

Holland, A.K., \& Harrison, D.W. (in press). An extension of the functional cerebral systems approach to hostility: A capacity model utilizing a dual concurrent task paradigm. Journal of Clinical and Experimental Neuropsychology.

Howes, D., \& Boller, F. (1975). Simple reaction times: Evidence for focal impairment from lesions of the right hemisphere. Brain, 98(2), 317-332.

Hugdahl, K. (1995). Dichotic listening: Probing temporal lobe functional integrity. In R. J. Davidson \& K. Hugdahl (Eds.), Brain Asymmetry (pp. 123-156). Cambridge: MIT Press. Hugdahl, K. (2002). Dichotic listening in the study of auditory laterality. In K. Hugdahl \& R. J. Davidson (Eds.), The Asymmetrical Brain (pp. 441-476). Cambridge: MIT Press.

Imaizumi, S., Mori, K., Kiritani, S., Kawashima, R., Sugiura, M., \& Fukuda, H. (1997). Vocal identification of speaker and emotion activates different brain regions. NeuroReport, 8(12), 2809-2812. doi: 10.1097/00001756-199708180-00031

Jacobs, G. D., \& Snyder, D. (1996). Frontal brain asymmetry predicts affective style in men. Behavioral Neuroscience, 110(1), 3-6. doi: 10.1037/0735-7044.110.1.3

Johnson, D. J. \& Hartlage, L. C. (1997). Neurobehavioral recovery following unilateral CVA. Archives of Clinical Neuropsychology, 12(4), 342-343. 
Kestenbaum, R., \& Nelson, C. A. (1992). Neural and behavioral correlates of emotion recognition in children and adults. Journal of Experimental Child Psychology, 54(1), 118. doi: 10.1016/0022-0965(92)90014-W

Kopp, B., \& Wessel, K. (2008). Neuropsychology of attention. Current Neurology, 35(1), 16-27. doi: $10.1055 / \mathrm{s}-2007-986253$

Lee, G. P., Loring, D. W., Meader, K. J., \& Brooks, B. B. (1990). Hemispheric specialization for emotion expression: A reexamination of results from intracarotid administration of sodium amobarbital. Brain and Cognition, 12(2), 267-280. doi: 10.1016/02782626(90)90019-K

Lee, G. P., Meador, K. J., Loring, D. W., Allison, J. D., Brown, W. S., Paul, L. K.,...Lavin, T. B. (2004). Neural substrates of emotion as revealed by functional magnetic resonance imaging. Cognitive and Behavioral Neurology, 17(1), 9-17. doi: 10.1097/00146965200403000-00002

Levy, B. R. (2003). Mind matters: Cognitive and physical effects of aging self-stereotypes. Journal of Gerontology, 58(4), 203-211. doi: 10.1093/geronb/58.4P203

Levy, J. (1969). Possible basis for the evolution of lateral specialization of the human brain. Nature, 224(5219), 614-615. doi: 10.1038/224614a0

Ley, R. G., \& Bryden, M. P. (1982). A dissociation of right and left hemispheric effects for recognizing emotional tone and verbal content. Brain and Cognition, 1, 3-9.

Mandel, M. K., Tandon, S. C., \& Asthana, H. S. (1991). Right brain damage impairs recognition of negative emotions. Cortex, 27, 247-253.

Mills, C. K. (1912a). The cerebral mechanisms of emotional expression. Transactions of the College of Physicians of Philadelphia, 34, 381-390.

Mills, C. K. (1912b). The cortical representation of emotion, with a discussion of some points in the general nervous mechanism of expression in its relation to organic nervous mental disease. Proceedings of the American Medico-Psychological Association, 19, 297-300.

Mollet, G. A., \& Harrison, D. W. (2006). Emotion and pain: A functional cerebral systems integration. Neuropsychological Review, 16(3), 99-121. doi: 10.1007/s11065-006-9009-3

Mollet, G. A., \& Harrison, D. W. (2007). Affective verbal learning in hostility: An increased primacy effect and bias for negative emotional material. Archives of Clinical Neuropsychology, 22, 53-61. doi: 10.1016/j.acn.2006.06.017 
Mondor, T. A., \& Bryden, M. P. (1992). On the relation between auditory spatial attention and auditory perceptual asymmetries. Perception and Psychophysics, 52, 393-402.

Munkong, R. \& Juan, B. H. (2008). Auditory perception and cognition. IEEE Signal Processing Magazine, 25(3), 98-117. doi: 10.1109/msp.2008.918418

Munte, T. F., Brack, M., Gootheer, O., Wieringa, B. M., Matzke, M., \& Johannes, S. (1998). Brain potentials reveal the timing of face identity and expression judgments. Neuroscience Research, 30(1), 25-34. doi: 10.1016/S0168-0102(97)00118-1

Narumoto, J., Okada, T., Sadato, N., Fukui, K., \& Yonekura, Y. (2001). Attention to emotion modulates fMRI activity in human right superior temporal sulcus. Cognitive Brain Research, 12(2), 225-241. doi: 10.1016/S0926-6410(01)00053-2

Petruzzello, S. J., Hall, E. E., \& Ekkekakis, P. (2001). Regional brain activation as a biological marker of affective responsivity to acute exercise: Influence of fitness. Psychophysiology, 38(1), 99-106. doi: 10.1111/1469-8986.3810099

Reuter-Lorenz, P. A., \& Davidson, R. J. (1981). Differential contributions of the two cerebral hemispheres to the perception of happy and sad faces. Neuropsychologia, 19(4), 609-613. doi: 10.1016/0028-3932(81)90030-0

Rey, A. (1964). L'Examin clinique en psychologie. Paris: Universitaire de France.

Rhodes, R. D., Hu, S. R., \& Harrison, D. W. (2000). Losing face: Diminished right frontal capacity in high-hostiles with facial and cardiovascular dystonia. Manuscript in preparation.

Robinson, R. G., Kubos, K. L., Starr, L. B., Rao, K., \& Price, T. R. (1984). Mood disorders in stroke patients: importance of location of lesion. Brain, 107(1), 81-93. doi: 10.1093/brain/107.1.81

Robinson, R. G., Parikh, R. M., Lipsey, J. R., \& Starkstein, S. E. (1993). Pathological laughing and crying following stroke: Validation of a measurement scale and a double-blind treatment study. American Journal of Psychiatry, 150(2), 286-293.

Roger, V.L., Go, A.S., Lloyd-Jones, D.M., Adams, R. J., Berry, J. D., Brown, T. M.,...WylieRosett, J. (2011). Heart disease and stroke statistics - 2011 Update: A report from the American Heart Association. Circulation, 123(4), e18-e209. doi: 10.1161/ CIR.0b013e3182009701 
Ross, E. (1985). Modulation of affect and nonverbal communication by the right hemisphere. In M-M. Mesulam (Ed.), Principles of behavioral neurology (pp. 239-257). Philadelphia, PA: F. A. Davis.

Sackeim, H. A., Greenberg, M. S., Weiman, A. L., Gur, R. C., Hungerbuhler, J. P., \& Geschwind, N. (1982). Hemispheric asymmetry in the expression of positive and negative emotions: Neurologic evidence. Archives in Neurology, 39(4), 210-218.

Sato, W., Kochiyama, T., Yoshikawa, S., Naito, E., \& Matsumura, M. (2004). Enhanced neural activity in response to dynamic facial expressions of emotion: An fMRI study. Cognitive Brain Research, 20(1), 81-91. doi: 10.1016/j.cogbrainres.2004.01.008

Schaffer, C. E., Davidson, R. J., \& Saron, C. (1983). Frontal and parietal electroencephalogram asymmetry in depressed and nondepressed subjects. Biological Psychiatry, 18(7), 753762.

Schmitt, J. J., Hartje, W., \& Willmes, K. (1997). Hemispheric asymmetry in the recognition of emotional attitude conveyed by facial expression, prosody, and propositional speech. Cortex, 33(1), 65-81.

Shearer, S. L., \& Tucker, D. M. (1981). Differential cognitive contributions of the cerebral hemispheres in the modulation of emotional arousal. Cognitive Therapy and Research, 5(1), 85-93. doi: 10.1007/BF01172328

Shenal, B. V., \& Harrison, D. W. (2003). Investigation of the laterality of hostility, cardiovascular regulation, and auditory recognition. International Journal of Neuroscience, 113, 205-222.

Shenal, B. V., Harrison, D. W., \& Demaree, H. A. (2003). The neuropsychology of depression: A literature review and preliminary model. Neuropsychology Review, 13(1), 33-42. doi: 10.1023/A:1022300622902

Shenal, B. V., Rhodes, R. D., \& Harrison, D. W. (2000). The effects of stress and affective list learning on cardiovascular reactivity: A model of dynamic cerebral laterality. Archives of Clinical Neuropsychology, 15(8), 771-772.

Silberman, E. K., \& Weingartner, H. (1986). Hemispheric lateralization of functions related to emotion. Brain and Cognition, 5(3), 322-353. doi: 10.1016/0278-2626(86)90035-7

Snyder, K. A., Harrison, D. W., \& Shenal, B. V. (1997). An affective auditory verbal learning test. Archives of Clinical Nueropsychology, 12(5), 477-482. 
Snyder, K. A., Harrison, D. W., \& Shenal, B. V. (1998). The affective auditory verbal learning test Peripheral arousal correlates. Archives of Clinical Neuropsychology, 13(3), 251-258.

Sperry, R. W. (1966). Brain bisection and mechanisms of consciousness. In J. C. Eccles (Ed.), Brain and conscious experience. New York: Springer-Verlag.

Sutton, S. K., \& Davidson, R. J. (2000). Prefrontal brain electrical asymmetry predicts the evaluation of affective stimuli. Neuropsychologia, 38(13), 1723-1733. doi: $10.1016 / \mathrm{S} 0028-3932(00) 00076-2$

Toglia, M. P., \& Battig, W. F. (1978). Handbook of word norms. Hillsdale, NJ: Lawrence Erlbaum.

Tomarken, A. J., Davidson, R. J., \& Henriques, J. B. (1990). Resting frontal brain asymmetry predicts affective responses to films. Journal of Personality and Social Psychology, 59(4), 91-801. doi: 10.1037/0022-3514.59.4.791

Tomarken, A. J., Davidson, R. J., Wheeler, R. E., \& Doss, R. C. (1992). Individual differences in anterior brain asymmetry and fundamental dimensions of emotion. Journal of Personality and Social Psychology, 62(4), 676-687. doi: 10.1037/0022-3514.62.4.676

Tucker, D. M. (1981). Lateral brain function, emotion, and conceptualization. Psychological Bulletin, 89(1), 19-46. doi: 10.1037/0033-2909.89.1.19

Tucker, D. M., \& Frederick, S. L. (1989). Emotion and brain lateralization. In: Wagner, H., \& Manstead, A. (Eds.), Handbook of Social Psychophysiology (pp. 27-70). New York, NY: Wiley.

Tucker, D. M., \& Newman, J. P. (1981). Verbal versus imaginal cognitive strategies in the inhibition of emotional arousal. Cognitive Therapy and Research, 5(2), 197-202. doi: 10.1007/BF01172527

Tucker, D. M., Roth, R. S., Arneson, B. A., \& Buckingham, V. (1977). Right hemisphere activation during stress. Neuropsychologia, 15(4-5), 697-700. doi: 10.1016/00283932(77)90076-8

Van Orden, G. C., Pennington, B. F., \& Stone, G. O. (2001). What do double dissociations prove? Cognitive Science, 25, 111-172. doi: 10.1207/s15516709cog2501_5

Vanderploeg, R. D., Brown,W. S., \&Marsh, J. T. (1987). Judgments of emotion in words and faces: ERPcorrelates. International Journal of Psychophysiology, 5(3), 193-205. doi: 10.1016/0167-8760(87)90006-7 
Welte, P. O. (1993). Indices of verbal learning and memory deficits after right hemisphere stroke. Archives of Physical Medicine and Rehabilitation, 74(6), 631-636.

Wheeler, R. E., Davidson, R. J., \& Tomarken, A. J. (1993). Frontal brain asymmetry and emotional reactivity: A biological substrate of affective style. Psychophysiology, 30(1), 82-89.

Winer, B. J. (1971). Statistical principles in experimental design. New York: McGraw Hill.

Wittling, W. (1990). Psychophysiological correlates of human brain asymmetry: Blood pressure changes during lateralized presentation of an emotionally laden film. Neuropsychologia, 28(5), 457-470. doi: 10.1016/0028-3932(90)90072-V

Wittling, W. (1997a). The right hemisphere and the human stress response. In B. Folkow, T. Schmidt, \& K. Uvnas-Moberg (Eds.), Stress, health, and the social environment. James $P$. Henry's integrative ethological approach to medicine reflected by recent research in humans and animals, in memory of a great 20th century physiologist (Ada Physiologica Scandinavica, Supplement), 640, pp. 55-59. Göteborg: Blackwell Science.

Wittling, W., \& Roschmann, R. (1993). Emotion-related hemisphere asymmetry: Subjective emotional responses to laterally presented films. Cortex, 29(3), 431-448.

Yesavage, J.A., Brink, T.L., Rose, T.L., Lum, O., Huang, V., Adey, M.B., \& Leirer, V.O. (1983). Development and validation of a geriatric depression screening scale: A preliminary report. Journal of Psychiatric Research, 17, 37-49. 
Table 1

Frequency table for CVA location, gender, age, and years of education

\begin{tabular}{|c|c|c|}
\hline Variable & $\mathrm{n}$ & $\%$ \\
\hline \multicolumn{3}{|l|}{ CVA Location } \\
\hline Left Hemisphere & 11 & 52.38 \\
\hline Male & 5 & 23.81 \\
\hline Female & 6 & 28.57 \\
\hline Right Hemisphere & 10 & 47.62 \\
\hline Male & 6 & 28.57 \\
\hline Female & 4 & 19.05 \\
\hline \multicolumn{3}{|l|}{ Gender } \\
\hline Male & 11 & 52.38 \\
\hline Female & 10 & 47.62 \\
\hline \multicolumn{3}{|l|}{ Age } \\
\hline $30-39$ & 1 & 4.76 \\
\hline $40-49$ & 1 & 4.76 \\
\hline $50-59$ & 0 & 0.00 \\
\hline $60-69$ & 4 & 19.05 \\
\hline $70-79$ & 7 & 33.33 \\
\hline $80-89$ & 8 & 38.10 \\
\hline \multicolumn{3}{|l|}{ Education } \\
\hline$<12$ years & 4 & 19.05 \\
\hline 12 years & 10 & 47.62 \\
\hline$>12$ years & 7 & 33.33 \\
\hline
\end{tabular}


Table 2

Mean scores for MAS, AAVLT, and Dichotic Listening performance between CVA groups

\begin{tabular}{|c|c|c|c|c|}
\hline \multirow[b]{2}{*}{ Response Type } & \multicolumn{2}{|c|}{$\underline{\mathrm{LCVA}}$} & \multicolumn{2}{|c|}{$\underline{\mathrm{RCVA}}$} \\
\hline & $M$ & $S D$ & $M$ & $S D$ \\
\hline Mood Assessment Scale & 9.36 & 5.41 & 9.44 & 4.95 \\
\hline \multicolumn{5}{|l|}{ AAVLT } \\
\hline Words Recalled & 5.43 & 2.78 & 5.26 & 2.15 \\
\hline Neutral & 5.16 & 3.14 & 5.56 & 2.19 \\
\hline Positive & 5.64 & 2.47 & 5.08 & 1.91 \\
\hline Negative & 5.54 & 2.70 & 5.14 & 2.34 \\
\hline \multicolumn{5}{|l|}{ Dichotic Listening Test } \\
\hline Total Detections & 13.58 & 5.96 & 15.80 & 4.30 \\
\hline Left Ear Detections & 7.62 & 3.98 & 5.08 & 2.67 \\
\hline Pre-Neutral & 6.82 & 2.89 & 4.90 & 2.42 \\
\hline Post-Neutral & 7.70 & 5.06 & 4.90 & 3.11 \\
\hline Pre-Positive & 8.30 & 4.64 & 5.40 & 2.88 \\
\hline Post-Positive & 7.60 & 4.00 & 5.20 & 2.70 \\
\hline Pre-Negative & 7.60 & 4.14 & 4.90 & 2.77 \\
\hline Post-Negative & 7.70 & 5.56 & 4.90 & 3.11 \\
\hline Right Ear Detections & 7.07 & 3.71 & 10.72 & 5.81 \\
\hline Pre-Neutral & 5.82 & 2.99 & 9.30 & 4.14 \\
\hline Post-Neutral & 7.60 & 3.75 & 10.60 & 6.20 \\
\hline Pre-Positive & 7.10 & 4.41 & 11.10 & 6.40 \\
\hline Post-Positive & 7.20 & 3.39 & 10.30 & 5.70 \\
\hline Pre-Negative & 7.40 & 3.66 & 10.50 & 6.50 \\
\hline Post-Negative & 7.40 & 4.60 & 12.50 & 6.60 \\
\hline
\end{tabular}

Note. $N=21 ;$ BOLD $p<.05$. 
Table 3

Mean scores for HR and SPO2 measures between CVA groups

\begin{tabular}{lcccc}
\hline & \multicolumn{2}{c}{ LCVA } & \multicolumn{2}{c}{ RCVA } \\
Response Type & $M$ & $S D$ & $M$ & $S D$ \\
\hline Heart Rate & & & & \\
Baseline & 80.82 & 17.14 & 75.35 & 15.38 \\
Pre-Neutral & 82.05 & 15.71 & 76.95 & 17.06 \\
Post-Neutral & 76.95 & 17.06 & 75.95 & 14.60 \\
Pre-Positive & 77.65 & 15.34 & 74.90 & 14.39 \\
Post-Positive & 79.00 & 15.68 & 75.45 & 15.35 \\
Pre-Negative & 78.45 & 17.28 & 75.93 & 16.06 \\
Post-Negative & 77.25 & 15.71 & 77.05 & 17.29 \\
Pulse Oxygen Saturation & & & & \\
Baseline & 95.82 & 1.97 & 95.20 & 1.80 \\
Pre-Neutral & 96.14 & 2.38 & 94.85 & 1.72 \\
Post-Neutral & 95.77 & 3.32 & 95.60 & 1.93 \\
Pre-Positive & 96.00 & 1.99 & 95.05 & 1.89 \\
Post-Positive & $\mathbf{9 6 . 7 0}$ & $\mathbf{1 . 3 8}$ & $\mathbf{9 5 . 2 0}$ & $\mathbf{1 . 6 4}$ \\
Pre-Negative & 95.85 & 1.97 & 94.85 & 1.81 \\
Post-Negative & 96.4 & 1.24 & 95.90 & 1.73 \\
& & & & \\
\hline
\end{tabular}

Note. $N=21 ;$ Heart Rate $=$ BPM; Pulse Oxygen Saturation $=\% ;$ BOLD $p<.05$ 
Table 4

Mean number of words recalled on each trial of the AAVLT between CVA groups

\begin{tabular}{|c|c|c|c|c|}
\hline \multirow[b]{2}{*}{ Trial } & \multicolumn{2}{|c|}{$\underline{\mathrm{LCVA}}$} & \multicolumn{2}{|c|}{$\underline{\mathrm{RCVA}}$} \\
\hline & $M$ & $S D$ & $M$ & $S D$ \\
\hline \multicolumn{5}{|l|}{ Neutral List } \\
\hline Trial 1 & 3.45 & 1.69 & 3.70 & 1.77 \\
\hline Trail 2 & 4.64 & 2.94 & 5.20 & 1.81 \\
\hline Trial 3 & 5.73 & 3.32 & 5.70 & 2.36 \\
\hline Trial 4 & 5.64 & 3.47 & 6.20 & 1.75 \\
\hline Trial 5 & 6.36 & 3.59 & 7.00 & 2.11 \\
\hline \multicolumn{5}{|l|}{ Positive List } \\
\hline Trial 1 & 4.80 & 1.87 & 3.80 & 1.62 \\
\hline Trail 2 & 5.20 & 2.04 & 5.20 & 1.81 \\
\hline Trial 3 & 5.50 & 2.12 & 4.80 & 2.04 \\
\hline Trial 4 & 6.20 & 2.82 & 5.20 & 1.75 \\
\hline Trial 5 & 6.50 & 3.31 & 6.40 & 1.71 \\
\hline \multicolumn{5}{|l|}{ Negative List } \\
\hline Trial 1 & 3.90 & 1.66 & 3.30 & 1.42 \\
\hline Trail 2 & 5.40 & 2.55 & 5.00 & 1.94 \\
\hline Trial 3 & 5.70 & 2.63 & 6.10 & 2.92 \\
\hline Trial 4 & 6.20 & 2.86 & 5.50 & 1.96 \\
\hline Trial 5 & 6.50 & 3.31 & 5.80 & 2.49 \\
\hline
\end{tabular}




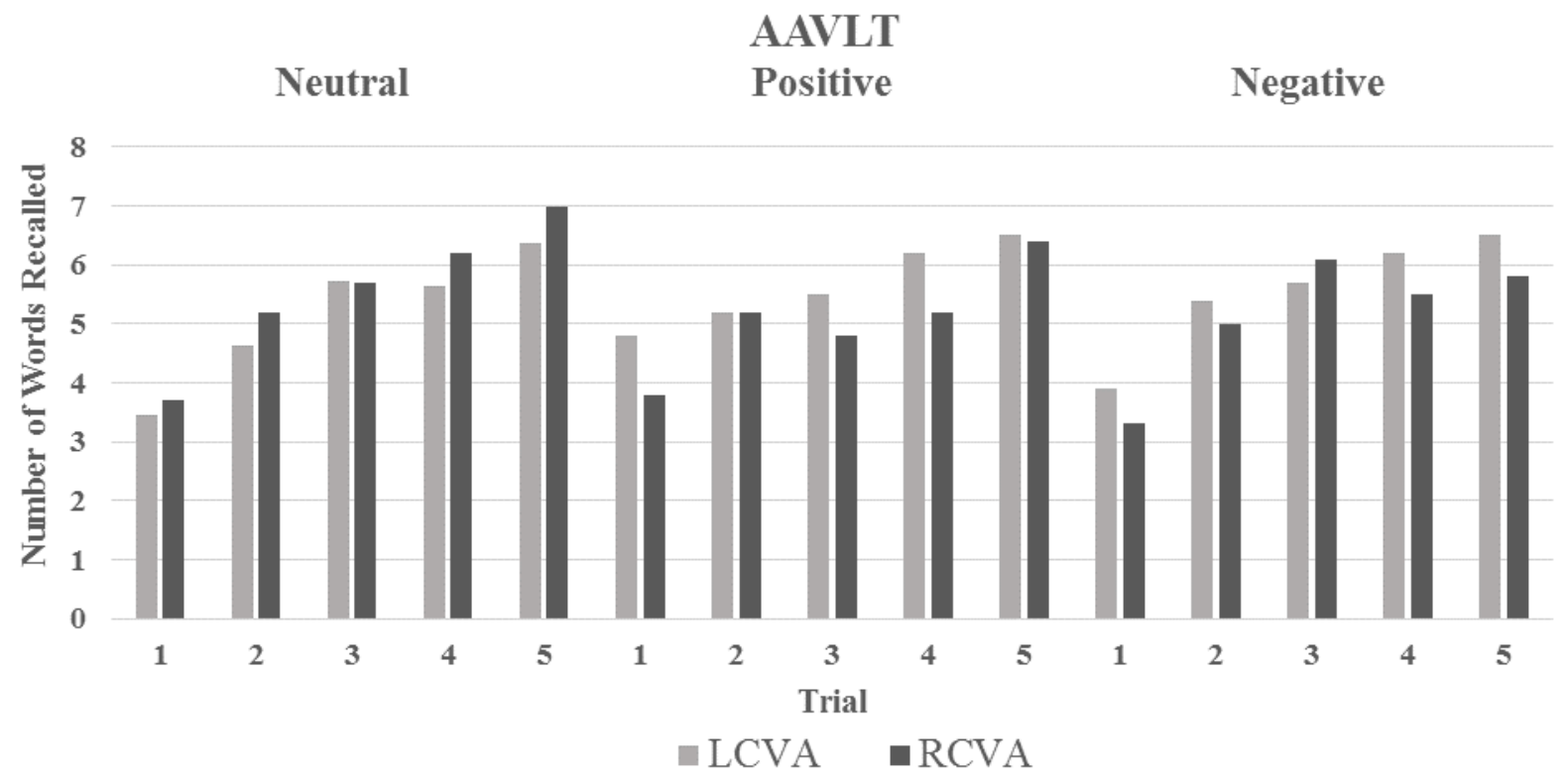

Figure 1. Mean number of words recalled at each trial for each list by left and right CVA patients. 


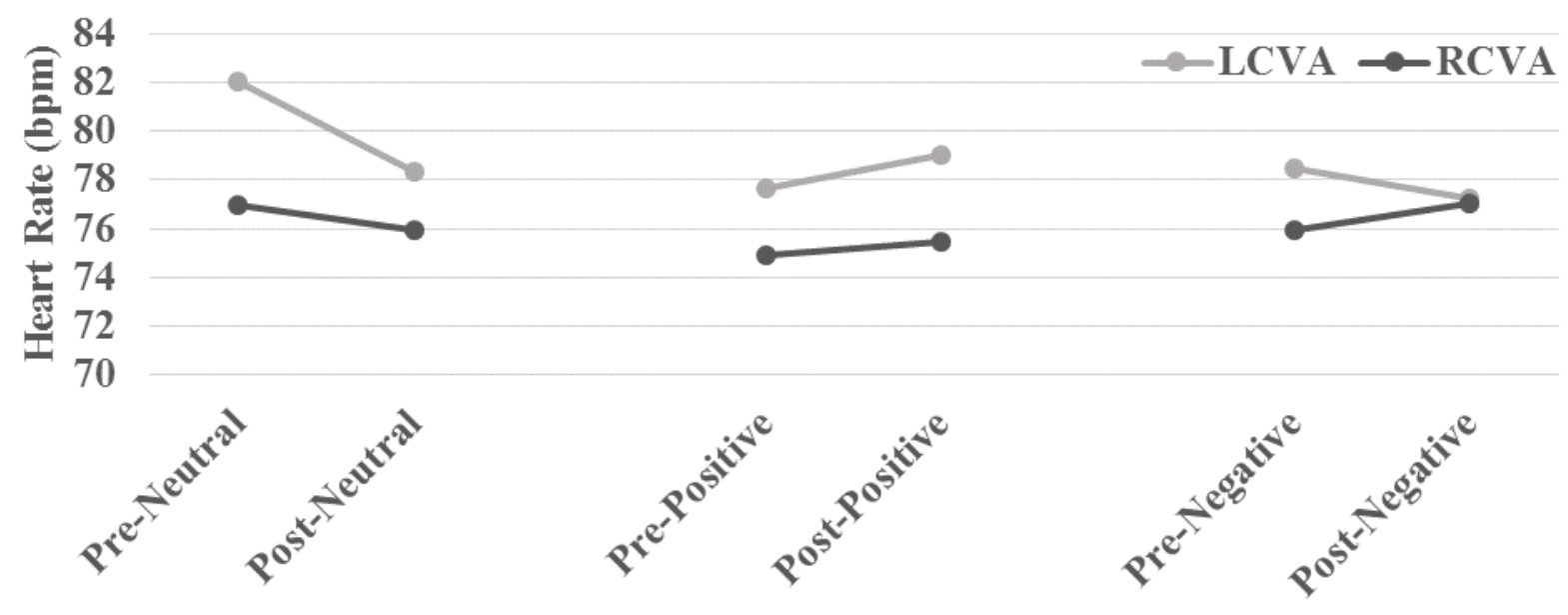

AAVLT Condition

Figure 2. Mean heart rate at each condition for each list by left and right CVA patients. 


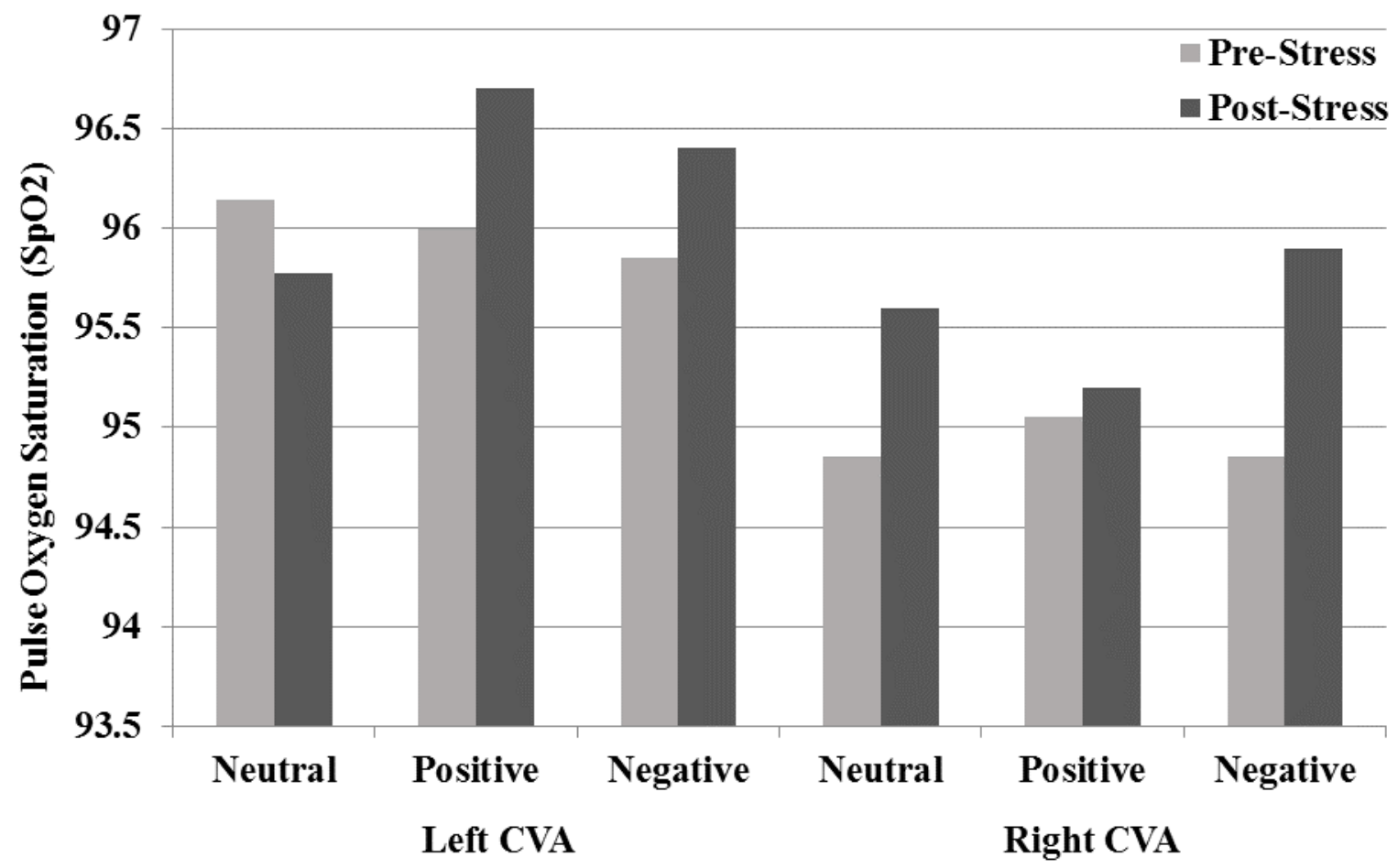

Figure 3. Mean pulse oxygen saturation levels at each condition for each list by left and right CVA patients. 


\section{Appendix A}

Dichotic Listening Test

\begin{tabular}{|c|c|c|c|c|c|}
\hline Trial & Left Track & Right Track & Trail & Left Track & Right Track \\
\hline 1 & pa & $\mathrm{ka}$ & 16 & da & ga \\
\hline 2 & da & $\mathrm{ka}$ & 17 & $\mathrm{ka}$ & pa \\
\hline 3 & $\mathrm{ka}$ & ta & 18 & pa & ta \\
\hline 4 & pa & ba & 19 & da & ta \\
\hline 5 & $\mathrm{ka}$ & $\mathrm{da}$ & 20 & ba & pa \\
\hline 6 & $\mathrm{ga}$ & $\mathrm{ka}$ & 21 & ba & ga \\
\hline 7 & ta & $\mathrm{ka}$ & 22 & da & ba \\
\hline 8 & ta & ga & 23 & ga & $\mathrm{da}$ \\
\hline 9 & ba & da & 24 & ta & da \\
\hline 10 & ga & ta & 25 & ka & ga \\
\hline 11 & ta & ba & 26 & ba & ta \\
\hline 12 & $\mathrm{ka}$ & ba & 27 & pa & $\mathrm{ga}$ \\
\hline 13 & ga & pa & 28 & pa & da \\
\hline 14 & ga & ba & 29 & ba & $\mathrm{ka}$ \\
\hline 15 & $\mathrm{da}$ & pa & 30 & ta & $\mathrm{pa}$ \\
\hline
\end{tabular}

\section{Stimulus Card Choices}

ba da ga ka pa ta 


\section{Appendix B}

Affective Auditory Verbal Learning Test

$\underline{\text { Neutral List }}$

Drum

Curtain

Bell

Coffee

School

Parent

Moon

Garden

Hat

Farmer

Nose

Turkey

Color

House

River
Positive List

Smile

Freedom

Cheerful

Friend

Music

Joy

Нарру

Wisdom

Blossom

Laugh

Beauty

Peace

Sunset

Garden

Beach
Negative List

Morgue

Murder

Kill

Pimple

Gun

Greedy

Lice

Measles

Slay

Deface

Cruel

Failing

Hate

Ache

Grave 


\section{Appendix C}

Coren-Porac-Duncan Laterality Test

Circle the appropriate number after each item:

With which hand would you throw a ball to hit a target?

With which hand do you draw?

With which hand do you use an eraser on paper?

With which hand do you remove the top card when dealing?

With Which foot do you kick a ball?

If you wanted to pick up a pebble with your toes, which foot would you use?

If you had to step up onto a chair, which foot would you place on the chair first?

Which eye would you use to peep through a keyhole?

If you had to look into a dark bottle to see how full it was, which eye would you use?

Which eye would you use to sight down a rifle?

If you wanted to listen to a conversation going on behind a closed door, which ear would you place against the door?

If you wanted to listen to someone's heartbeat, which ear would you place against their chest?

Into which ear would you place the earphone of a transistor radio?

\# of Right + \# of Left $=$ Total Score
Right Left Both

$$
\begin{array}{lll}
1 & -1 & 0 \\
1 & -1 & 0 \\
1 & -1 & 0 \\
1 & -1 & 0 \\
1 & -1 & 0
\end{array}
$$

$\begin{array}{lll}1 & -1 & 0\end{array}$

$\begin{array}{lll}1 & -1 & 0\end{array}$

$\begin{array}{lll}1 & -1 & 0\end{array}$

$\begin{array}{lll}1 & -1 & 0\end{array}$

$\begin{array}{lll}1 & -1 & 0\end{array}$

$\begin{array}{lll}1 & -1 & 0\end{array}$

$\begin{array}{lll}1 & -1 & 0\end{array}$

$\begin{array}{lll}1 & -1 & 0\end{array}$ 


\section{Appendix D}

\section{Mood Assessment Scale}

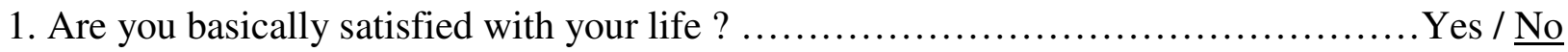

2. Have you dropped many of your activities and interests ? ...................... Yes / No

3. Do you feel that your life is empty ? ........................................ No

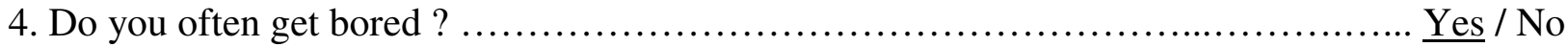

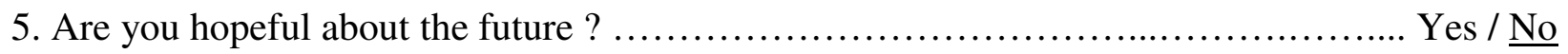

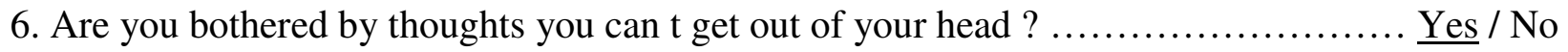

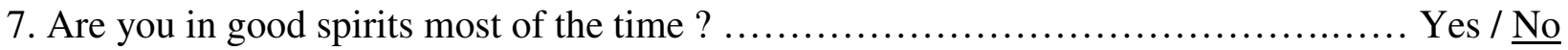

8. Are you afraid that something bad is going to happen to you ? .................. Yes / No

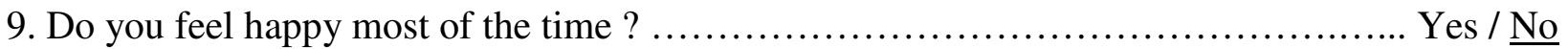

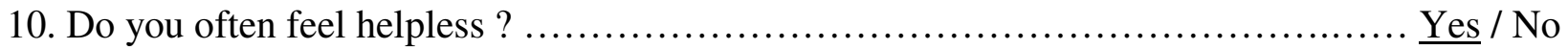

11. Do you often get restless and fidgety ? ...................... Yes $/$ No

12. Do you prefer to stay at home, rather than going out and doing new things ? ........ Yes / No

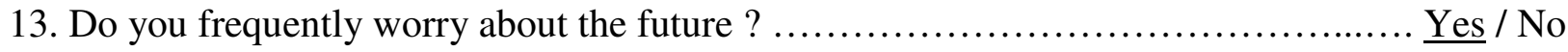

14. Do you feel you have more problems with memory than most $? . \ldots \ldots \ldots \ldots \ldots \ldots \ldots$ Yes $/$ No

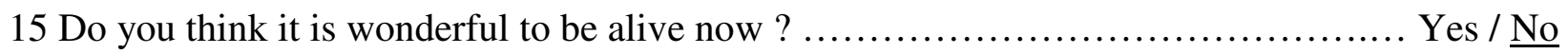

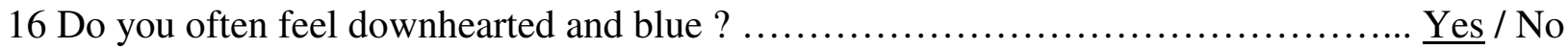

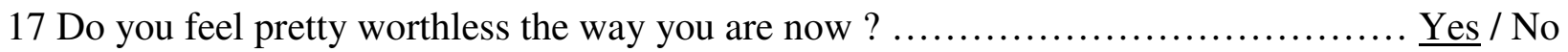

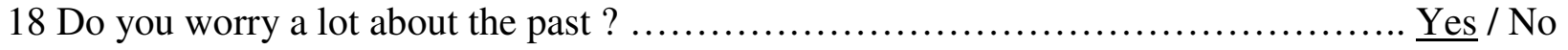

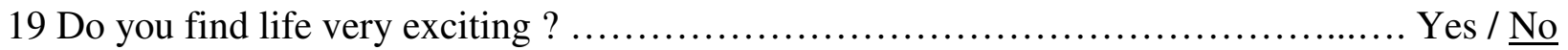

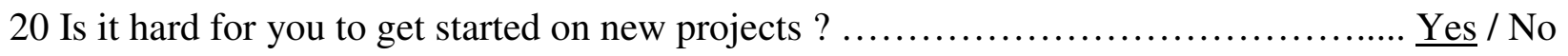

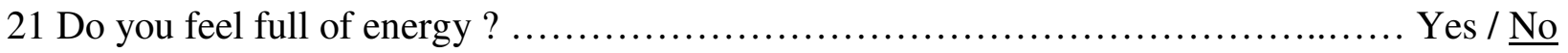


22 Do you feel that your situation is hopeless? $\underline{\text { Yes } / \text { No }}$

23 Do you think that most people are better off than you are ? $\underline{\text { Yes } / \text { No }}$

24 Do you frequently get upset over little things ? $\underline{\text { Yes } / \text { No }}$

25 Do you frequently feel like crying ? $\underline{\text { Yes } / \text { No }}$

26 Do you have trouble concentrating? $\underline{\text { Yes } / \text { No }}$

27 Do you enjoy getting up in the morning ? Yes / No

28 Do you prefer to avoid social gatherings ? $\underline{\text { Yes } / \mathrm{No}}$

29 Is it easy for you to make decisions ? Yes / $\underline{\text { No }}$

30 Is your mind as clear as it used to be ? Yes / No

One point for each of the underlined answers.

Cutoff: normal-0-9; mild depression-10-19; severe depression-20-30. 
Appendix E

Linear Progression of Positive List before Negative List Procedure

\begin{tabular}{|c|c|c|c|c|c|c|}
\hline \multicolumn{2}{|c|}{ HR\&SpO2 } & \multicolumn{2}{|c|}{ HR\&SpO2 } & \multicolumn{2}{|c|}{ HR\&SpO2 } & HR\&SpO2 \\
\hline Dichotic & NEUTRAL & Dichotic & POSITIVE & Dichotic & NEGATIVE & Dichotic \\
\hline $\mathrm{HR} \& \mathrm{SpC}$ & & HR\&SpC & & HR\&SpC & & HR\&SpO2 \\
\hline
\end{tabular}


Appendix F

Linear Progression of Negative List before Positive List Procedure

\begin{tabular}{|c|c|c|c|c|c|c|}
\hline \multicolumn{2}{|c|}{ HR\&SpO2 } & \multicolumn{2}{|c|}{ HR\&SpO2 } & \multicolumn{2}{|c|}{ HR\&SpO2 } & HR\&SpO2 \\
\hline Dichotic & NEUTRAL & Dichotic & NEGATIVE & Dichotic & POSITIVE & Dichotic \\
\hline $\mathrm{HR} \& \mathrm{SpC}$ & & HR\&SpO & & HR\&Sp & & HR\&SpO2 \\
\hline
\end{tabular}

